$<$ Supporting information $>$

\title{
Polymer Interfacial Self-Assembly Guided Two-dimensional Engineering of Hierarchically Porous Carbon Nanosheets
}

Seongseop Kim, ${ }^{+, \neq}$Mieun Ju, ${ }^{\S, \dagger}$ Jisung Lee, ${ }^{\dagger}$ Jongkook Hwang, ${ }^{*,+}$ and Jinwoo Lee ${ }^{*,+}$

${ }^{+}$Department of Chemical and Biomolecular Engineering, Korea Advanced Institute of Science and Technology (KAIST), 291 Daehak-ro, Daejeon 34141, Republic of Korea

${ }^{\S}$ Department of Chemical Engineering, Pohang University of Science and Technology (POSTECH), 77 Cheongam-Ro, Nam-Gu, Pohang 37673, Gyeongbuk, Republic of Korea

E-mail: jongkook@ajou.ac.kr, jwlee1@kaist.ac.kr

${ }^{\ddagger}$ These authors contributed equally. 


\section{Method}

Materials. Homo-poly(methyl methacrylate) (hPMMA) (350 $\left.\mathrm{kg} \mathrm{mol}^{-1}\right)$, homo-polystyrene (hPS) (350 kg mol$\left.{ }^{-1}\right)$, poly(melamine-co-formaldehyde) (melamine resin, $\left.\mathrm{MR}\right)\left(\mathrm{M}_{\mathrm{n}}=\sim 432 \mathrm{~g} \mathrm{~mol}^{-1}, 84 \mathrm{wt} \%\right.$ in 1-butanol), aluminum sec-butoxide $\left(\mathrm{Al}\left(\mathrm{OBu}^{\mathrm{s}}\right)_{3}\right)$, (3-glycidyloxypropyl-)trimethoxysilane (Glymo), phenol, formaldehyde solution ( $37 \mathrm{wt} \%$ in $\mathrm{H}_{2} \mathrm{O}$ ) and Pluronic F127 were purchased from SigmaAldrich. Chloroform $\left(\mathrm{CHCl}_{3}\right)$, tetrahydrofuran (THF), and concentrated $\mathrm{HCl}(35-37 \%)$ were purchased from Samchun (Korea). Phenol-formaldehyde resin (RF) was synthesized by previously

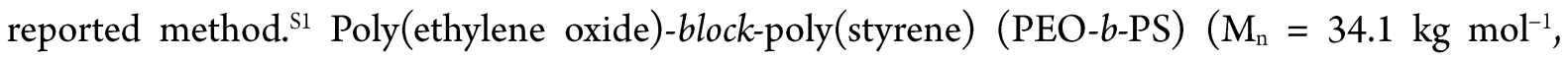
polydispersity index $(\mathrm{PDI})=1.36$ and $14.7 \mathrm{wt} \% \mathrm{PEO} ; \mathrm{M}_{\mathrm{n}}=52.0 \mathrm{~kg} \mathrm{~mol}^{-1}, \mathrm{PDI}=1.30$ and $9.6 \mathrm{wt} \%$ PEO) and poly(ethylene oxide)-block-poly(methyl methacrylate) (PEO-b-PMMA) (29.4 kg mol-1, $\mathrm{PDI}=1.74$ and $17.0 \mathrm{wt} \% \mathrm{PEO})$ was also prepared by atom transfer radical polymerization .

Synthesis of phenol-formaldehyde resin (PF). $5 \mathrm{~g}$ of Phenol was melted at $50^{\circ} \mathrm{C}$ in a round bottom flask. After then, $1.1 \mathrm{~g}$ of $20 \mathrm{wt} \% \mathrm{NaOH}$ aqueous solution was slowly added under stirring. After 10 min, $8.6 \mathrm{~g}$ of formaldehyde solution was added to phenol solution. The phenol and formaldehyde were reacted into $\mathrm{PF}$ at $70{ }^{\circ} \mathrm{C}$ for $1 \mathrm{~h}$ with stirring, and the solution was cooled to room temperature. The PF solution was neutralized using $2 \mathrm{M} \mathrm{HCl}$. Water was removed under vacuum at $50^{\circ} \mathrm{C}$. To precipitate salt produced during neutralization, THF was poured into the $\mathrm{PF} /$ salt mixture. After $\mathrm{NaCl}$ removal by filtration, THF was removed in the vacuum oven at $40^{\circ} \mathrm{C}$.

Synthesis of aluminosilicate sol (AS sol). $0.313 \mathrm{~g}$ of glymo, 2.703 of aluminum sec-butoxide, and $0.011 \mathrm{~g}$ of $\mathrm{KCl}$ were mixed in an ice bath for $5 \mathrm{~min}$. Then $0.135 \mathrm{~g}$ of $0.01 \mathrm{M} \mathrm{HCl}$ was added slowly. The solution was stirred for $15 \mathrm{~min}$, then removed from ice bath and stirred for another $15 \mathrm{~min}$. Then 0.765 
$\mathrm{g}$ of $0.01 \mathrm{M} \mathrm{HCl}$ was added dropwise over a period of $10 \mathrm{~min}$; the solution was stirred for $25 \mathrm{~min}$, then filtered through a $0.2 \mu \mathrm{m}$ PTFE syringe filter to remove $\mathrm{KCl} .^{\mathrm{S} 2}$

Synthesis of hierarchical porous N-doped carbon nanosheets (HNCNSs) and nanodisks. First, $2 \mathrm{~g}$ of hPMMA and $2 \mathrm{~g}$ of hPS were dissolved in $\mathrm{CHCl}_{3}$ to make a $10 \mathrm{wt} \%$ polymeric solution. Then resol: MR: PEO-b-PS: AS sol: THF was mixed at the mass ratio of 3: 3: 5: 30: 1000 in another container. PEO- $b$-PS has the molar mass of $34.1 \mathrm{~kg} \mathrm{~mol}^{-1}$ and polydispersity index (PDI) of 1.36, and the weight ratio of PEO to $\mathrm{BCP}$ is $17.0 \mathrm{wt} \%$. This mixture was added to the polymeric solution. After 30 min stirring, it was poured into the petri dish. $\mathrm{CHCl}_{3}$ and $\mathrm{THF}$ was evaporated fast at $40{ }^{\circ} \mathrm{C}$ and then polymer/precursor hybrids were annealed at $100{ }^{\circ} \mathrm{C}$ for $24 \mathrm{~h}$. The as-made hybrids was carbonized at $800^{\circ} \mathrm{C}$ for $2 \mathrm{~h}$ under $\mathrm{Ar}$ atmosphere with the heating rate of $2{ }^{\circ} \mathrm{C} \mathrm{min}^{-1}$. To remove AS species for the generation of micropores, HNCNS-AS composites were immersed in $2 \mathrm{M} \mathrm{NaOH}$ solution for $4 \mathrm{~h}$ and washed with distilled water.

To obtain HNCNS with enlarged mesopores of $46 \mathrm{~nm}$, we used PEO-b-PS (52.0 $\mathrm{kg} \mathrm{mol}^{-1}$, $\mathrm{PDI}=1.30$ and $9.6 \mathrm{wt} \%$ PEO) with the increased PS molar mass.

The solvent rinsing procedure. To liberate the as-made BCP/AS/PF-MF nanosheets, hPMMA and hPS were removed by THF rinsing. The as-made hybrids were re-dissolved in THF after thermal annealing under vigorous stirring. In this procedure, hPMMA and hPS phases were rapidly dissolved in THF. However, the as-made BCP/AS/PF-MF nanosheets were only dispersed in THF because AS sols, $\mathrm{PF}$ and MF were already condensed by the acid catalyst and thermal curing at $100^{\circ} \mathrm{C}$. Such crosslinked organic-inorganic material is sufficiently robust to remain intact during THF rinsing. After THF rinsing for $10 \mathrm{~min}$, separation by centrifugation at $6000 \mathrm{rpm}$ yielded the as-made nanosheets, and these 
rinsing procedures were performed twice more for the removal of residual polymer phases. After drying the solvent at $50^{\circ} \mathrm{C}$, the as-made $\mathrm{BCP} / \mathrm{AS} / \mathrm{PF}-\mathrm{MF}$ hybrid nanosheets were obtained in a yield of $89 \%$.

Synthesis of 2D N-doped carbon nanodisks. To obtain ultra-thin 2D carbon nanodisks, a mixed solution with hPS $/ \mathrm{BCP}$ ratio $=200$ was used. The solution consisted of $0.01 \mathrm{~g}$ of PEO-b-PS, $0.006 \mathrm{~g}$ of resol, $0.006 \mathrm{~g}$ of MR, $0.06 \mathrm{~g}$ of AS and the same amounts of hPMMA and hPS that had been used to prepare HNCNS. The following procedure were identical to those employed for the preparation of HNCNS.

Synthesis of hierarchical porous $\mathbf{N}$-doped carbon spheres. To prepare hierarchical porous Ndoped carbon spheres, we used PEO-b-PMMA (29.4 $\mathrm{kg} \mathrm{mol}^{-1}$, PDI $=1.74$ and $\left.17.0 \mathrm{wt} \% \mathrm{PEO}\right)$ and Pluronic F127 as block copolymers instead of PEO-b-PS. When we used PEO-b-PMMA, $0.05 \mathrm{~g}$ of PEO- $b$-PMMA, $2 \mathrm{~g}$ of hPMMA, $2 \mathrm{~g}$ of hPS, $0.03 \mathrm{~g}$ of resol, $0.03 \mathrm{~g}$ of MR and $0.3 \mathrm{~g}$ of AS sol were dissolved in $20 \mathrm{~g}$ of $\mathrm{CHCl}_{3}$ and $16 \mathrm{~g}$ of THF. When $\mathrm{F} 127$ was used, the mixed solution containing 0.05 $\mathrm{g}$ of F127, $2 \mathrm{~g}$ of hPMMA, $2 \mathrm{~g}$ of hPS, $0.12 \mathrm{~g}$ of resol, $0.12 \mathrm{~g}$ of MR and $0.46 \mathrm{~g}$ of AS sol was prepared. The following procedures were identical for the synthesis of HNCNS.

Bulk hierarchical porous N-doped carbon. A mixed solution of PEO- $b$-PS: resol: MR: AS sol: THF (0.2 g: $0.1 \mathrm{~g}: 0.1 \mathrm{~g}: 0.4 \mathrm{~g}: 7.2 \mathrm{~g}$ ) was prepared. Subsequent procedures were identical to those used to synthesize HNCNS.

Materials Characterization. Gel permeation chromatography (GPC; Waters) was performed using THF as the eluent, and the molar mass was calibrated on the basis of PS standards. The structure of 2D hierarchical porous $\mathrm{N}$-doped carbon nanosheets were characterized by transmission electron 
microscopy (TEM, Tecnai F20, FEI company). As hPMMA phases of microtomed samples partially decomposed in the electron beam, contrast was obtained between the hPMMA and hPS phases without staining. In TEM images of microtomed samples, hPS and hPMMA phases appeared as gray and bright areas, respectively. BCP/AS/PF-MF phases appeared as dark areas due to the cross-linked AS and PF-MF. ${ }^{S 3}$ Scanning electron microscopy (SEM) was performed at $30 \mathrm{kV}$ using S-4200 field emission SEM (Hitach). The nitrogen physisorption was carried out at $77 \mathrm{~K}$ using a Tristar II 3020 (Micromeritics Instrument Co.). Powder X-ray diffraction (XRD) patterns were obtained using Rigaku D/MAX-2500/PC X-ray diffractometer ( $\mathrm{Cu} \mathrm{Ka}$ ). Atomic force microscopy (AFM) measurements were conducted using a Veeco Dimension 3100 instrument in tapping mode.

Electrochemical characterization. For the half-cell test, K metal and HNCNS or BHNC were used as counter and working electrode, respectively. The electrochemical performance of half-cell was tested in a half-cell configuration using CR2032-type coin cells assembled in a glove box. A GF/F glass microfiber filter (Whatman, USA) was used as a separator. The organic electrolyte was the $1 \mathrm{M}$ solution of potassium bis(fluorosulfonyl)imide (KFSI) dissolved in a mixture $(1: 1 \mathrm{v} / \mathrm{v})$ of ethylene carbonate (EC) and dimethyl carbonate (DMC). The working electrode was prepared via typical slurry and casting method. The slurry was made using mixture of $70 \mathrm{wt} \% \mathrm{HNCNS}$ or BHNC, $20 \mathrm{wt} \%$ super-p and $10 \mathrm{wt} \%$ carboxyl methyl cellulose (CMC) and then pasted on $\mathrm{Cu}$ foil. The galvanostatic electrochemical test was assessed by WBCS-3000 battery cycler (Wonatech Co., Korea) in the potential range of $0.01-3 \mathrm{~V}\left(v s . \mathrm{K} / \mathrm{K}^{+}\right)$. 

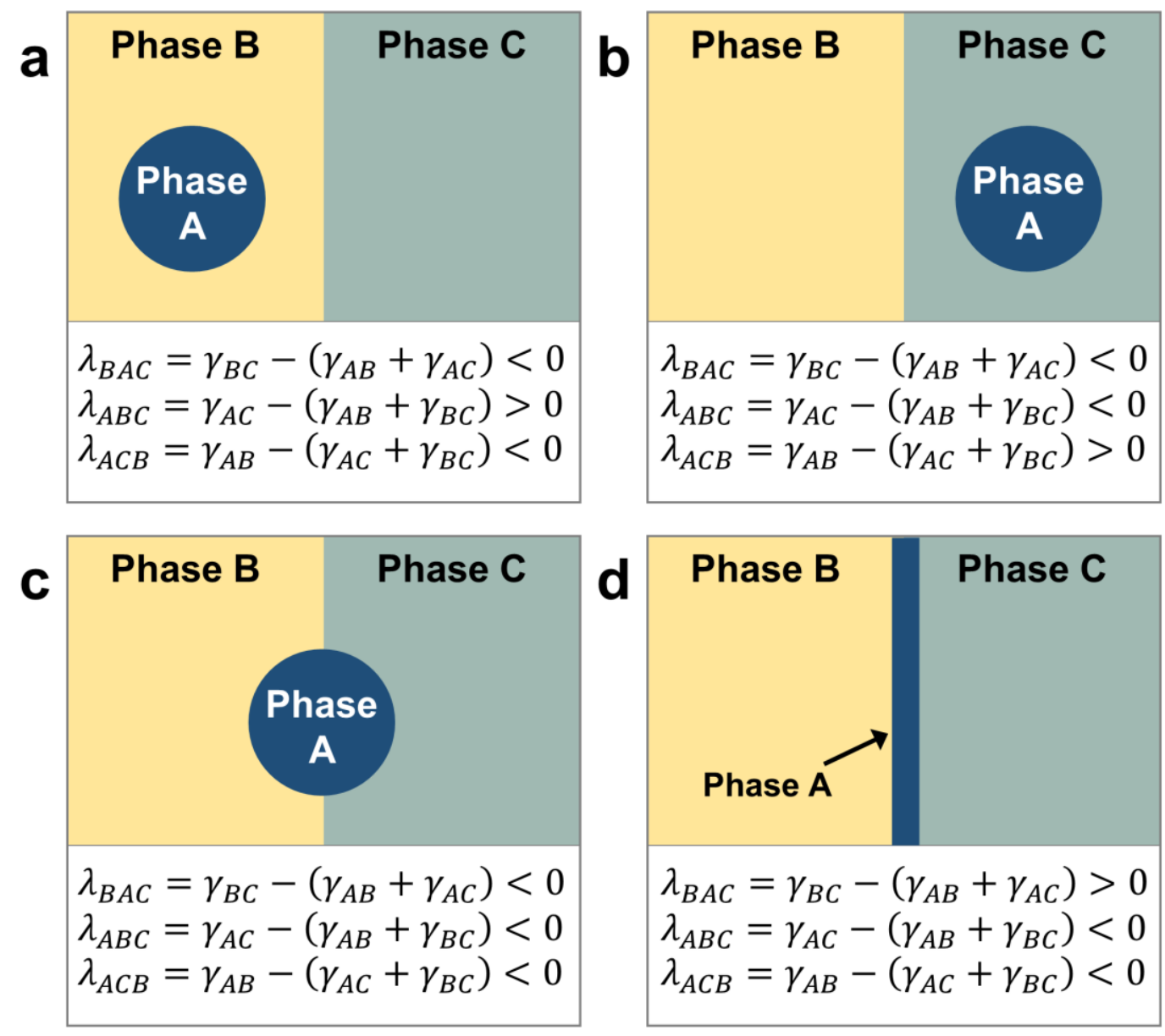

Figure S1. (a-d) Four possible morphologies and corresponding spreading coefficient and interfacial tension in ternary polymer blends composed of one minor phase $\mathrm{A}$ and two major phases $\mathrm{B}$ and phase C.

Ternary polymer blends composed of one minor phase $\mathrm{A}$ and two major phases $\mathrm{B}$ and phase $\mathrm{C}$ have four possible morphologies, which are determined by interfacial tension and spreading coefficient between phases (Figure S1a-d). The spreading coefficient $(\lambda)$ can be defined as

$$
\lambda_{i j k}=\gamma_{i k}-\left(\gamma_{i j}+\gamma_{j k}\right)
$$

where the $\gamma$ values are the interfacial tension between phases. The phase $\mathrm{A}$ is completely segregated into the phase $\mathrm{B}$ or $\mathrm{C}$ when the interfacial tension of $\mathrm{A} / \mathrm{C}$ or $\mathrm{A} / \mathrm{B}$ is higher than the others $\left(\gamma_{A C}>\right.$ 
$\gamma_{A B}+\gamma_{B C}$ or $\gamma_{A B}>\gamma_{A C}+\gamma_{B C}$ ) (Figure S1a, b). The phase A is partially wetted with both phase $\mathrm{B}$ and $\mathrm{C}$ when all $\lambda$ is negative (Figure S1c). The three phases meet each other by sharing their interfaces. When the interfacial tension of $\mathrm{B} / \mathrm{C}$ is significantly higher than of $\mathrm{A} / \mathrm{C}$ and $\mathrm{A} / \mathrm{B}\left(\gamma_{B C}>\right.$ $\left.\gamma_{A B}+\gamma_{A C}\right)$, phase A spreads evenly at the interface between phase B and C to decrease $\gamma_{B C}$. 

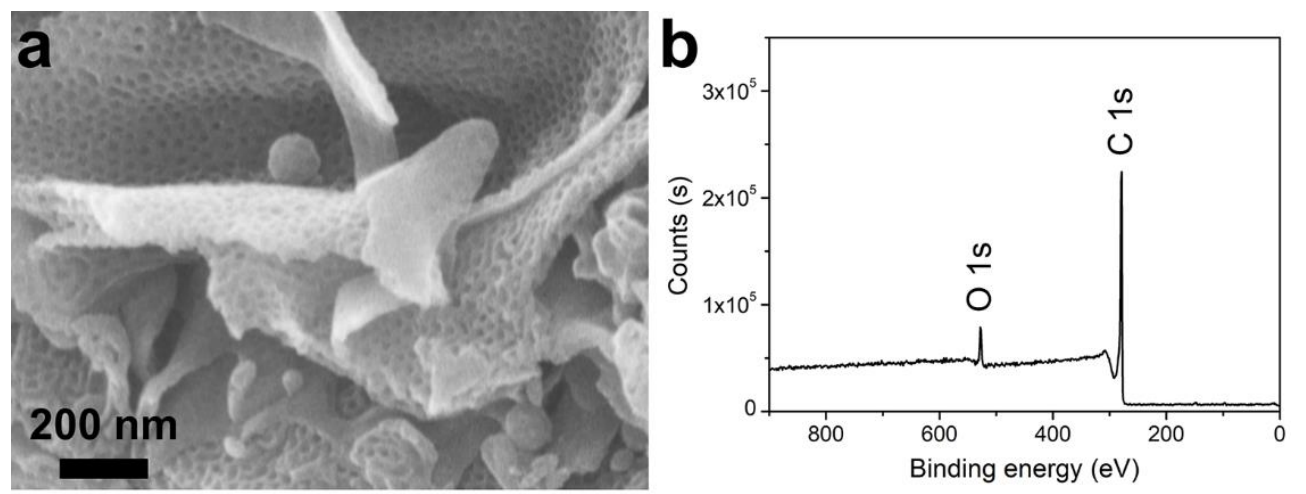

Figure S2. (a) SEM image and (b) XPS survey spectrum of nitrogen-free CNSs.

Nitrogen-free carbon nanosheets (CNS) had the same structural features as HNCNS: the ordered mesoporous structures and ultra-thin 2D morphology (Figure S2a). However, XPS analysis exhibited that nitrogen-free CNS is composed of $92.2 \% \mathrm{C}$ and $7.8 \% \mathrm{O}$ only; no nitrogen peak was detected in the binding energy around $400 \mathrm{eV}$ (Figure S3b). These results confirm that MF acts as nitrogen source and improves the $\mathrm{N}$ content of carbon materials during carbonization at $800^{\circ} \mathrm{C}$. 


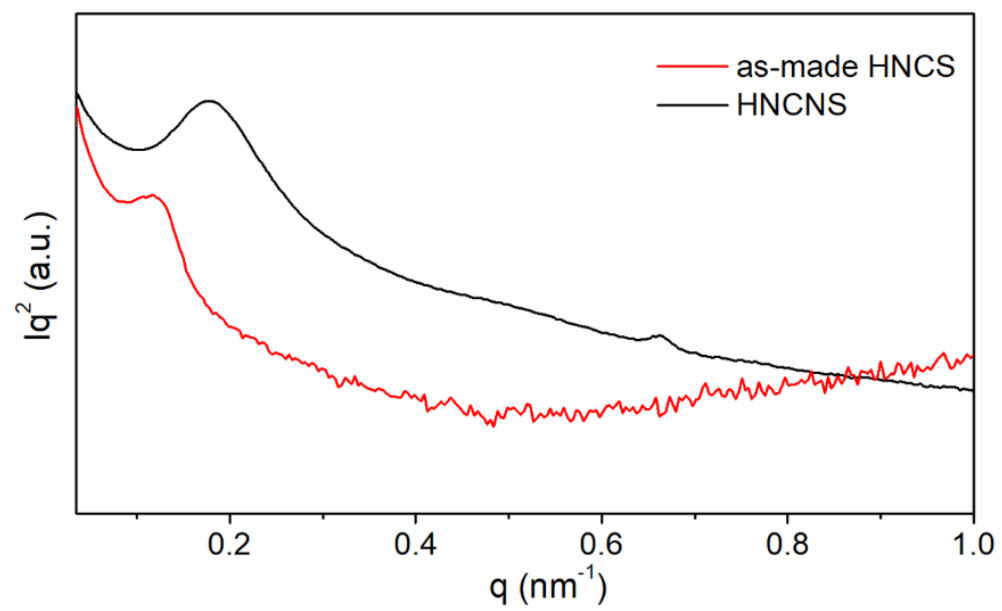

Figure S3. SAXS pattern of as-made HNCNS hybrids (red line) and HNCNS (black line). The main peak was shifted from 0.12 to $0.18 \mathrm{~nm}^{-1}$ due to thermal shrinkage after carbonization. 

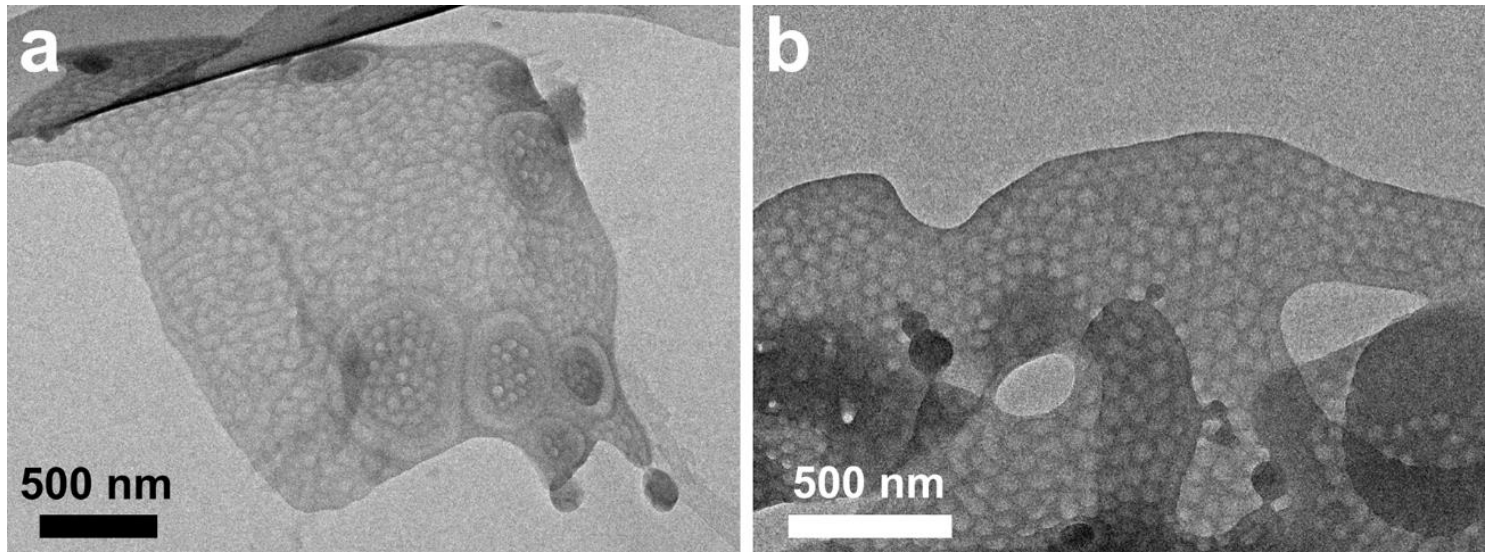

Figure S4. ( $a, b)$ TEM images of PEO- $b$-PS/AS/PF-MF hybrids after removing hPMMA and hPS phases by THF rinsing. These images reveal that PEO- $b$-PS/AS/PF-MF phase self-assembled at the hPMMA-hPS interface. 


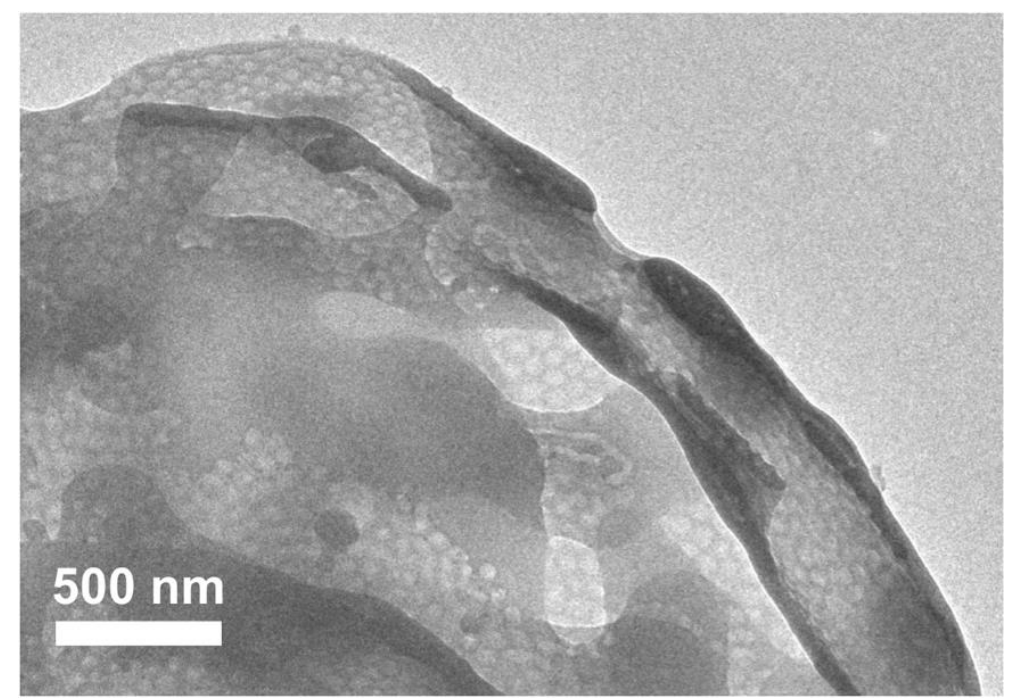

Figure S5. TEM image of the as-made PF-MF nanosheets after the removal of AS species via $\mathrm{NaOH}$ etching.

PF and MF can be thermally cross-linked together at $80-120{ }^{\circ} \mathrm{C}$ to form robust 3D polymeric networks. The PISA approach involved thermal annealing at $100{ }^{\circ} \mathrm{C}$ during which PF-MF was polymerized. The cross-linked PF-MF was no longer dissolved in THF due to their polymeric frameworks with excessively large molar mass. To investigate this, we removed hPMMA and hPS by THF rinsing and obtained the as-made BCP/AS/PF-MF hybrids nanosheets in a yield of $89 \%$. Subsequently, AS frameworks were removed via $\mathrm{NaOH}$ etching before carbonization and as-made BCP/PF-MF hybrids nanosheets were stirred in THF for $24 \mathrm{~h}$. Although AS species was removed, ordered mesostructures and $2 \mathrm{D}$ nanosheet morphology of polymeric $\mathrm{BCP} / \mathrm{PF}-\mathrm{MF}$ nanosheets remained intact. These results confirmed that the thermal annealing process improved the structural integrity, and therefore PF-MF as carbon precursors were stable against THF rinsing and even $\mathrm{NaOH}$ etching. 


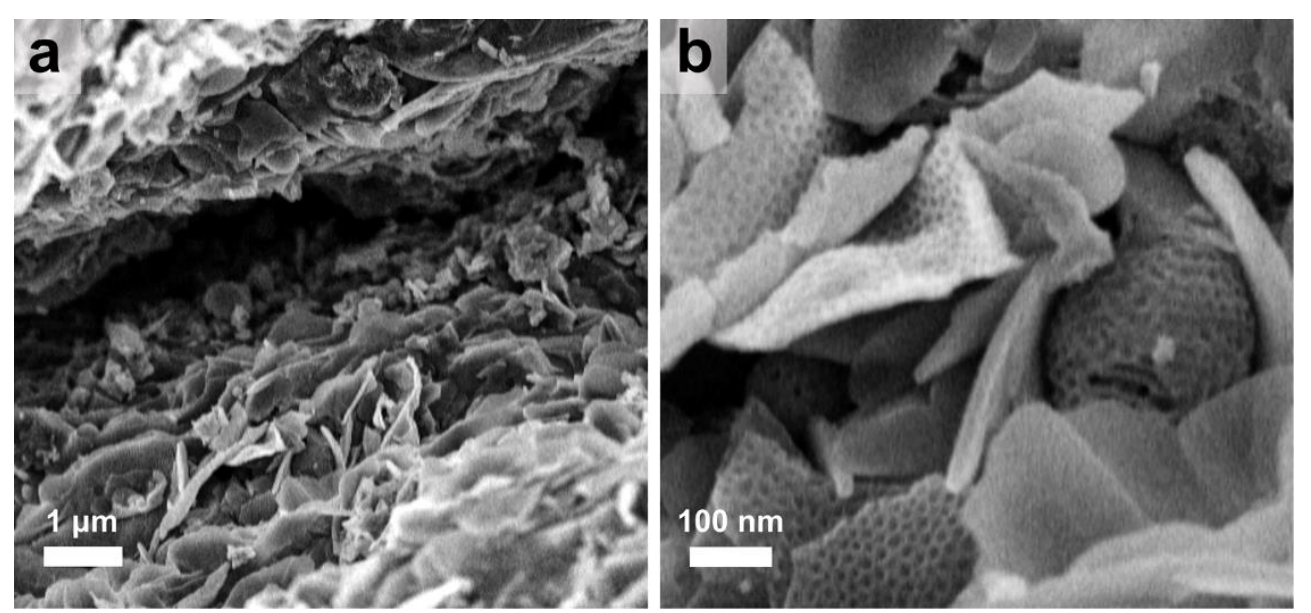

Figure S6. (a, b) SEM images of HNCNS after carbonization and $\mathrm{NaOH}$ etching. 

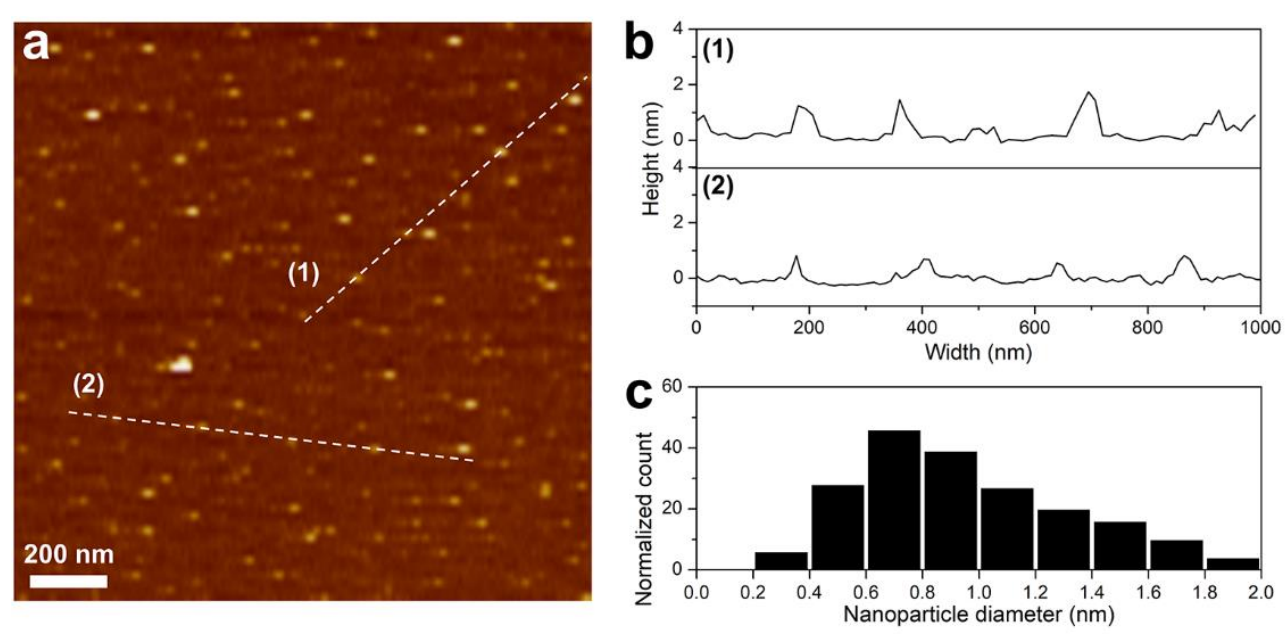

Figure S7. (a) AFM image, (b) the corresponding height profiles, and (c) The size distribution of AS nanoparticles.

To measure the size of AS species occupying the mesoporous frameworks, we estimated the size by using AS nanoparticles (NPs) derived from AS sol. The $5 \mathrm{wt} \%$ dilute solution of AS sol in THF was prepared and poured on a piece of silicon wafer, then was dried at $50^{\circ} \mathrm{C}$. After annealing at $100{ }^{\circ} \mathrm{C}$ and calcination at $800^{\circ} \mathrm{C}$, AS sol was converted to the AS NP on the wafer. The size of AS NPs was measured by AFM (Figure S7a, b) and 200 particles were counted for the size distribution. The size of AS NP was smaller than $2 \mathrm{~nm}$ and mainly distributed in the range of 0.4 to $1.4 \mathrm{~nm}$ (Figure S7c), which is in good agreement with the micropore size distribution of HNCNS (Figure 2h). 

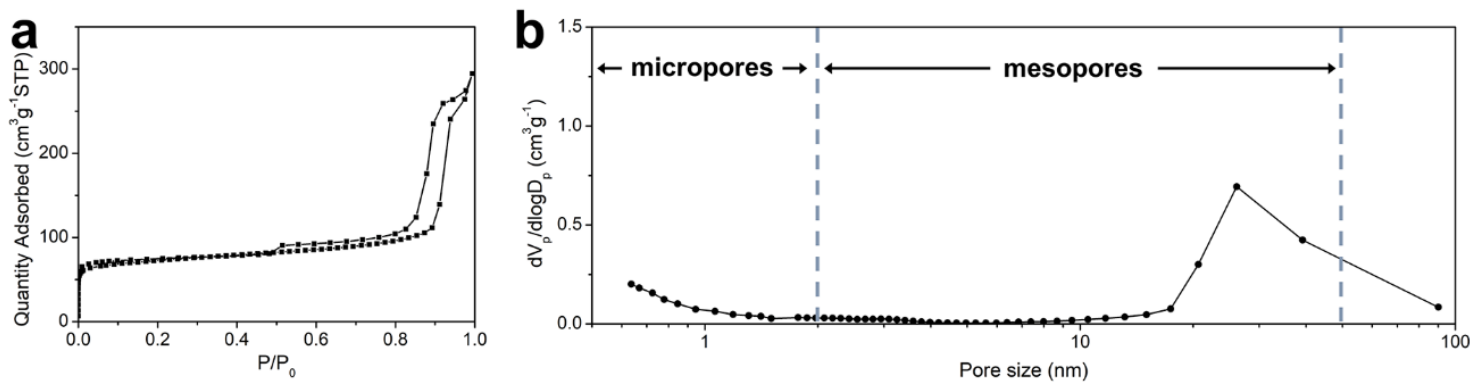

Figure S8 (a) $\mathrm{N}_{2}$ physisorption isotherm and (b) the pore size distribution curves of the mesoporous AS/NCNS composite. 


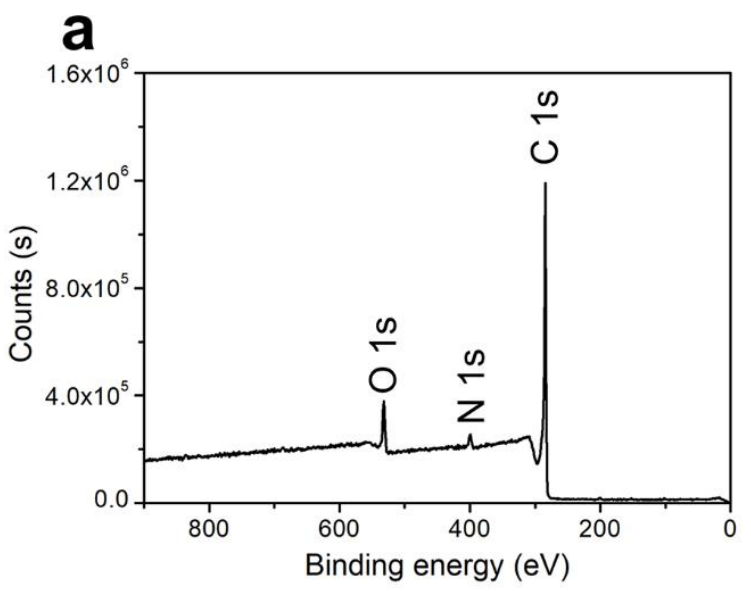

b

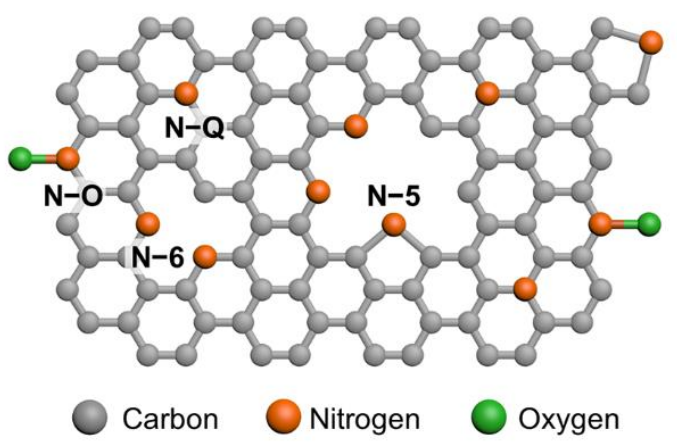

\section{C}

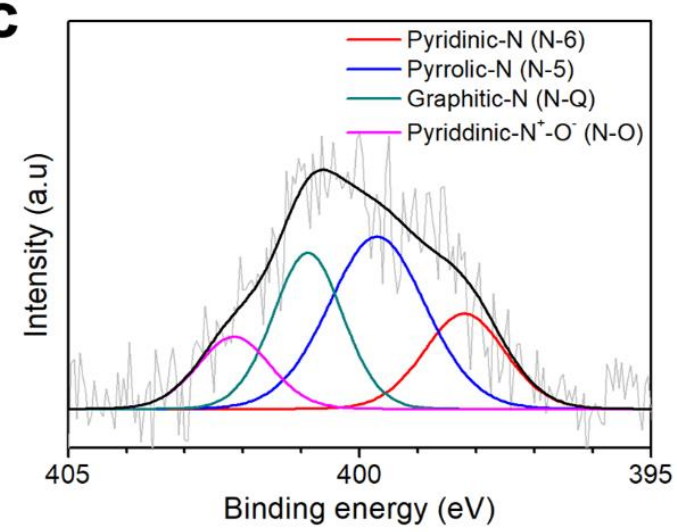

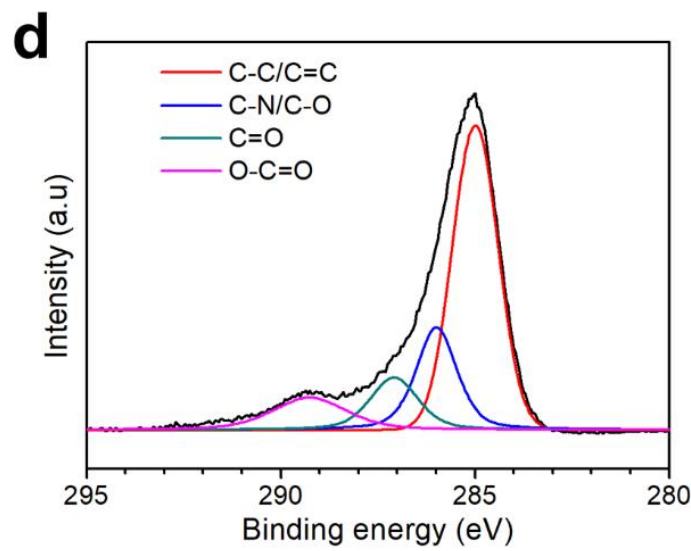

Figure S9. (a) XPS survey spectrum for HNCNS. (b) A schematic illustration of the N-doping positions. (c, d) High-resolution XPS spectra of N 1s (c) and C 1s (d) for HNCNS. 


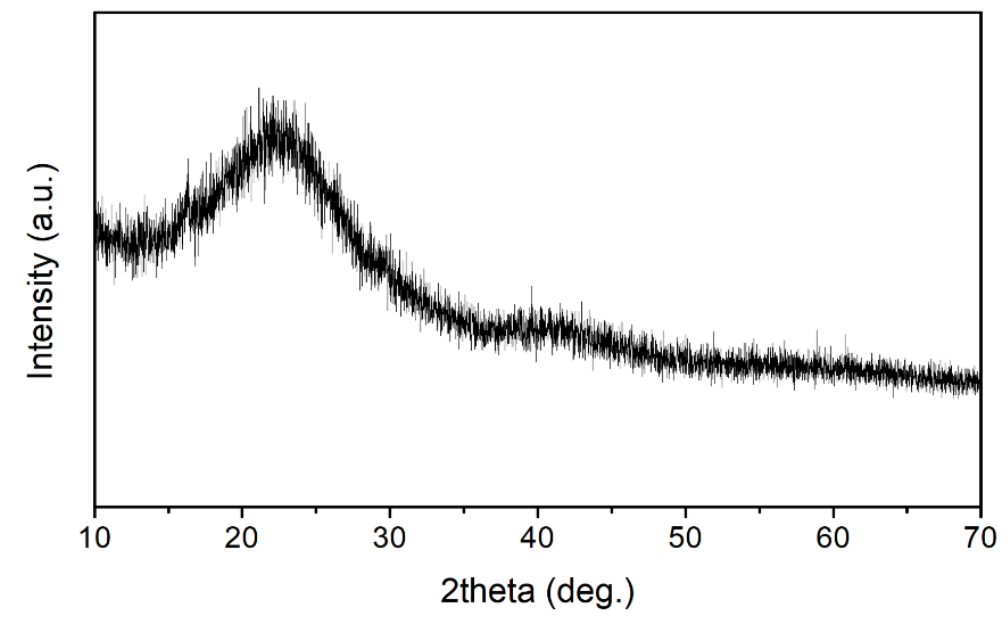

Figure S10. XRD pattern of HNCNS. 


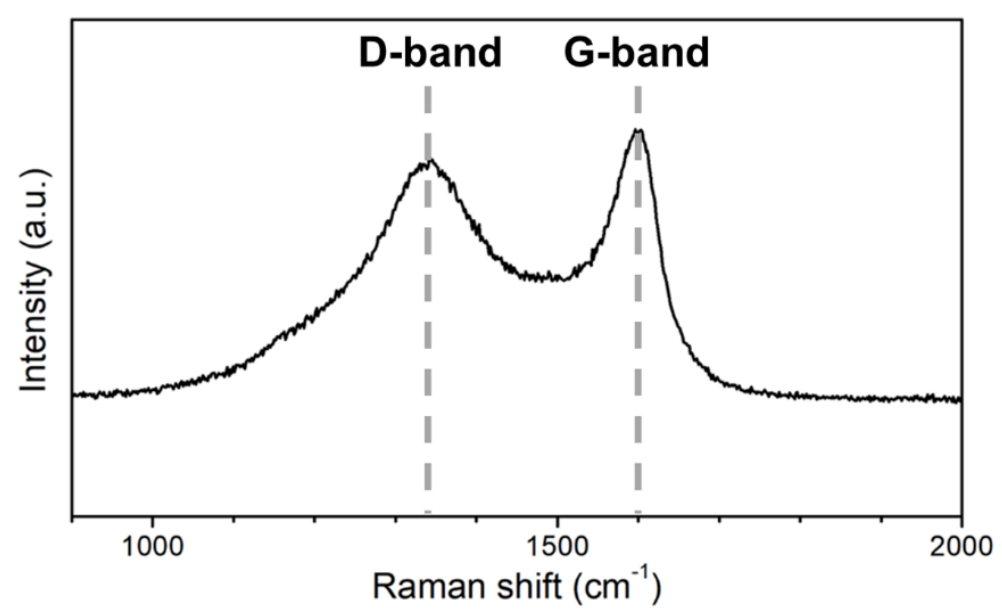

Figure S11. Raman spectrum of HNCNS. 

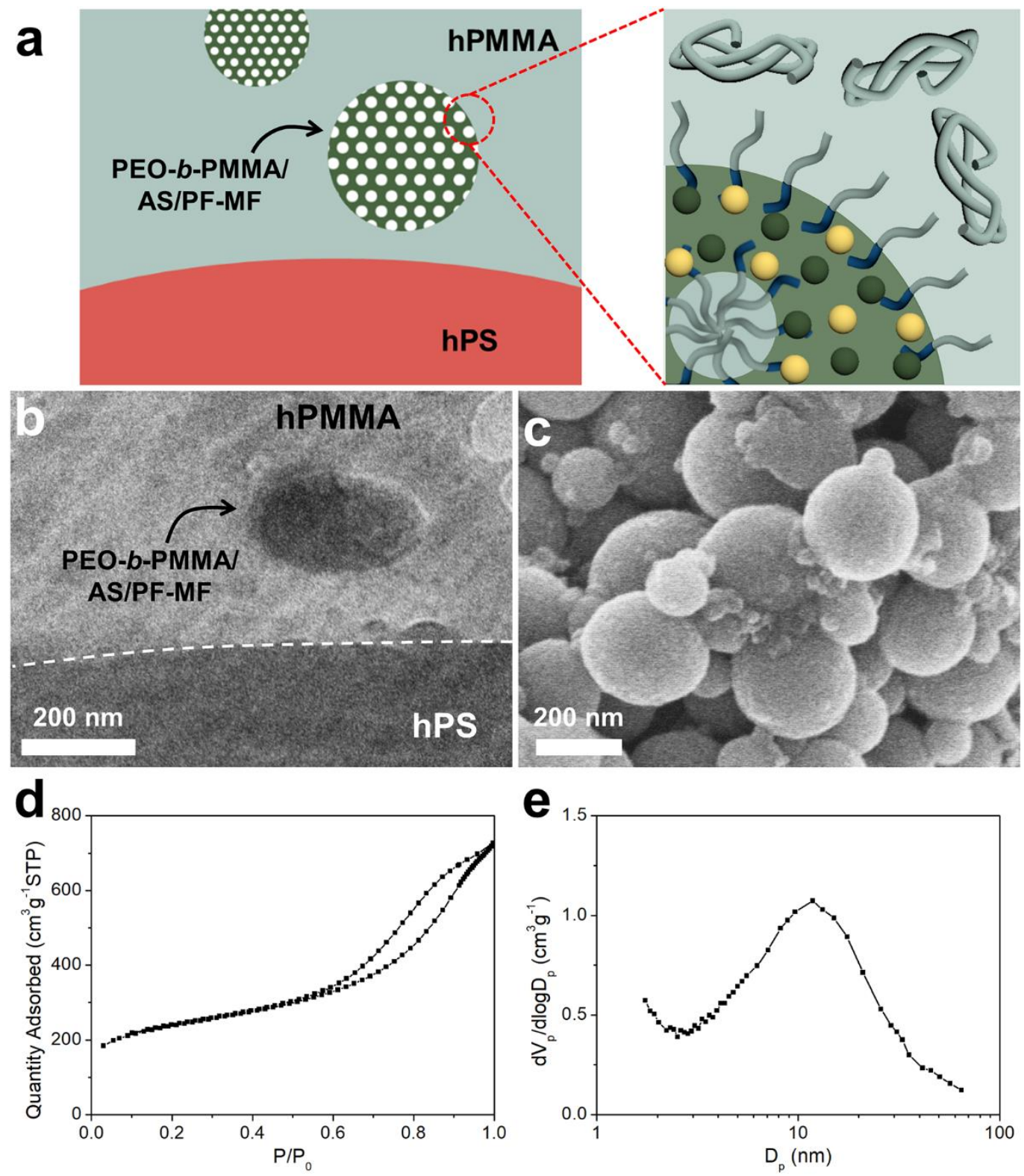

Figure S12. (a) Schematic representation of the formation of AS/PF-MF/PEO- $b$-PMMA hybrids and of orientation of PEO- $b$-PMMA at the interface between BCP-rich phase and hPMMA. (b) TEM image of microtomed AS/PF-MF/PEO- $b$-PMMA hybrids. (c) SEM image, (d) $\mathrm{N}_{2}$ physisorption isotherm and (e) corresponding pore size distribution of hierarchical porous $\mathrm{N}$-doped carbon spheres with the surface area of $790 \mathrm{~m}^{2} \mathrm{~g}^{-1}$ and mesopore of $12 \mathrm{~nm}$. 

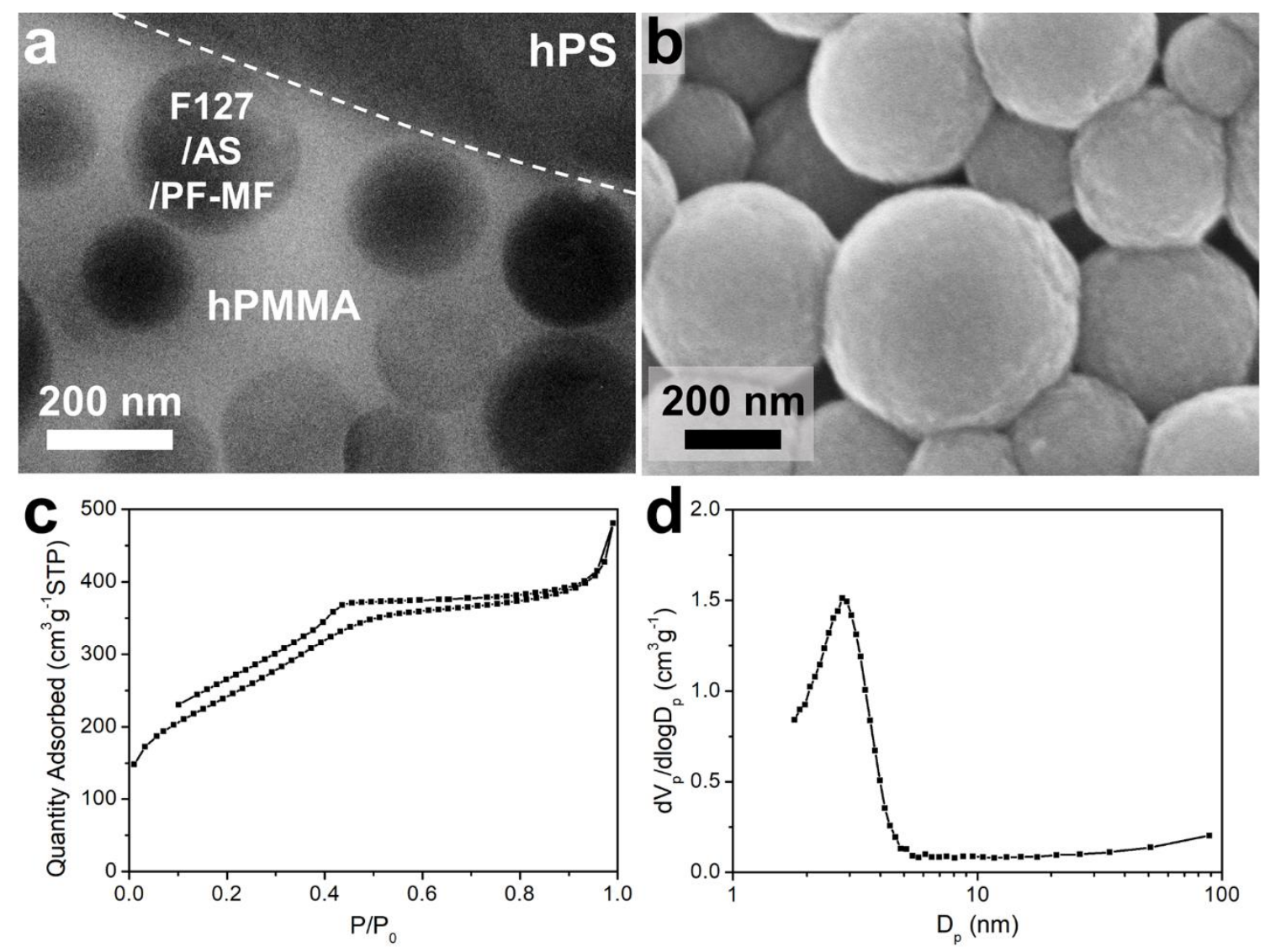

Figure S13. (a) TEM image of microtomed AS/PF-MF/PEO-b-PMMA hybrids. (b) SEM image, (c) $\mathrm{N}_{2}$ physisorption isotherm and (d) corresponding pore size distribution of hierarchical porous Ndoped carbon spheres with surface area of $863 \mathrm{~m}^{2} \mathrm{~g}^{-1}$ and mesopore of $2.9 \mathrm{~nm}$. 

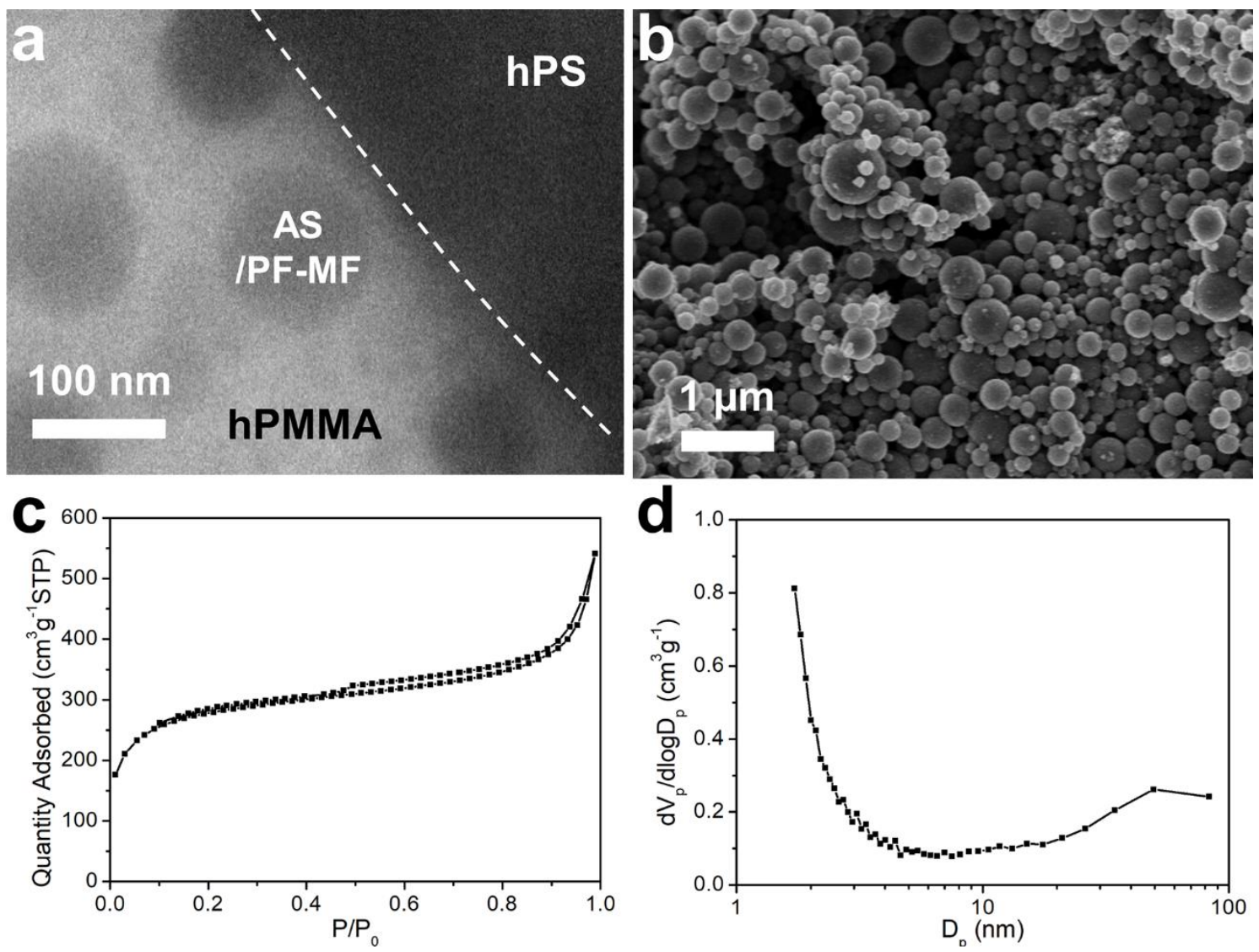

Figure S14. (a) TEM image of microtomed AS/PF-MF hybrids without BCP. (b) SEM image, (c) $\mathrm{N}_{2}$ physisorption isotherm and $(\mathrm{d})$ corresponding pore size distribution of microporous $\mathrm{N}$-doped carbon spheres without mesopores. 

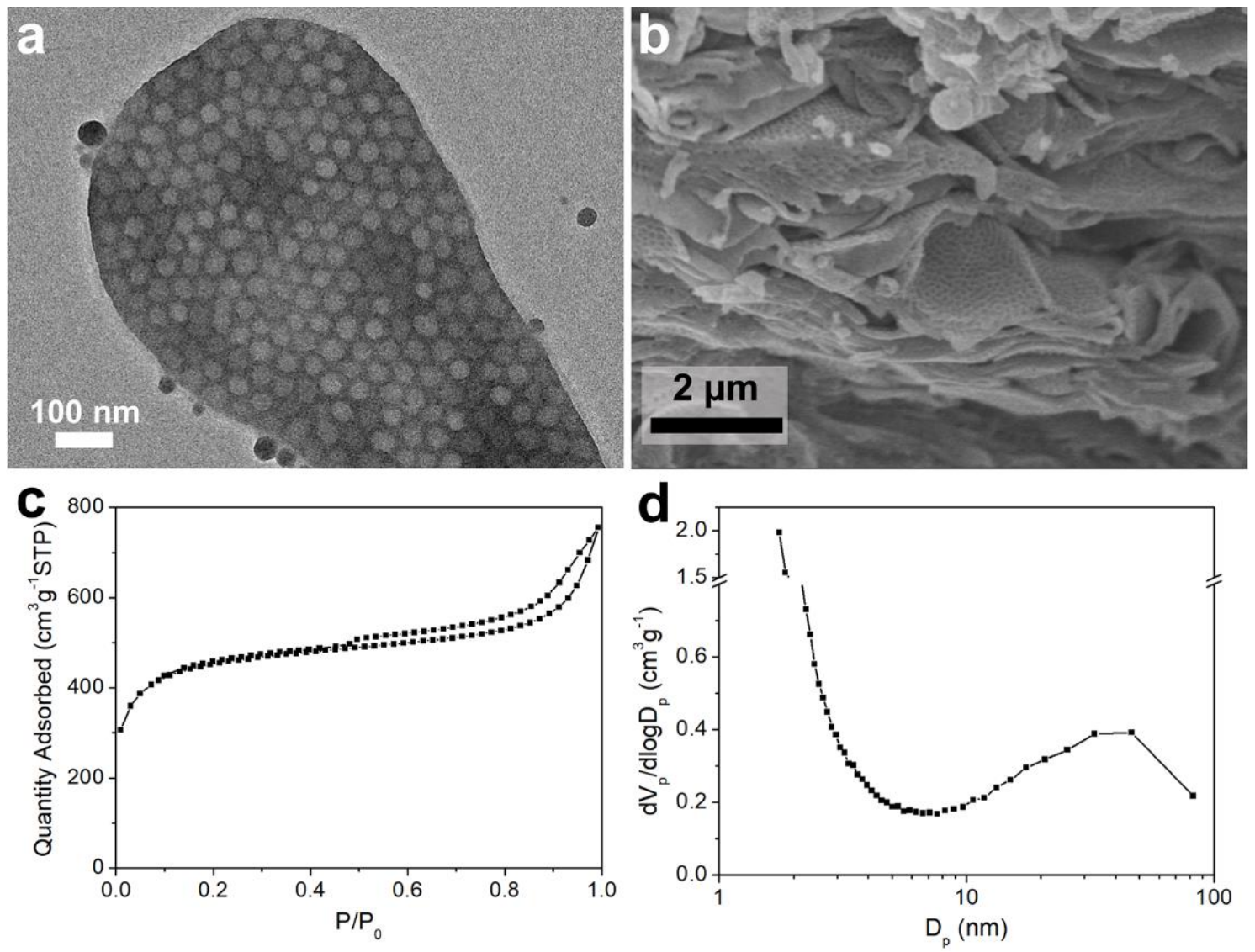

Figure S15. (a) TEM, (b) SEM images, (c) $\mathrm{N}_{2}$ physisorption and (d) corresponding pore size distribution of HNCNS with enlarged mesopores (46 nm). 

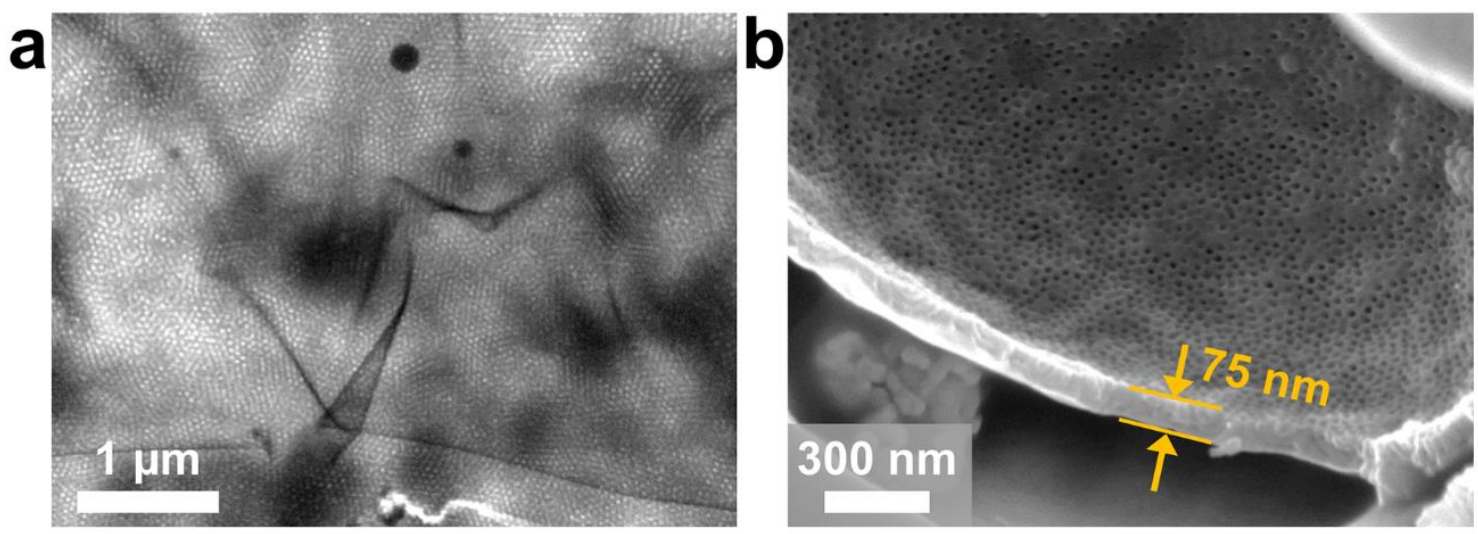

Figure S16. (a) TEM and (b) SEM images of thickness controlled HNCNS-20 and estimated thickness of $\sim 75 \mathrm{~nm}$. 

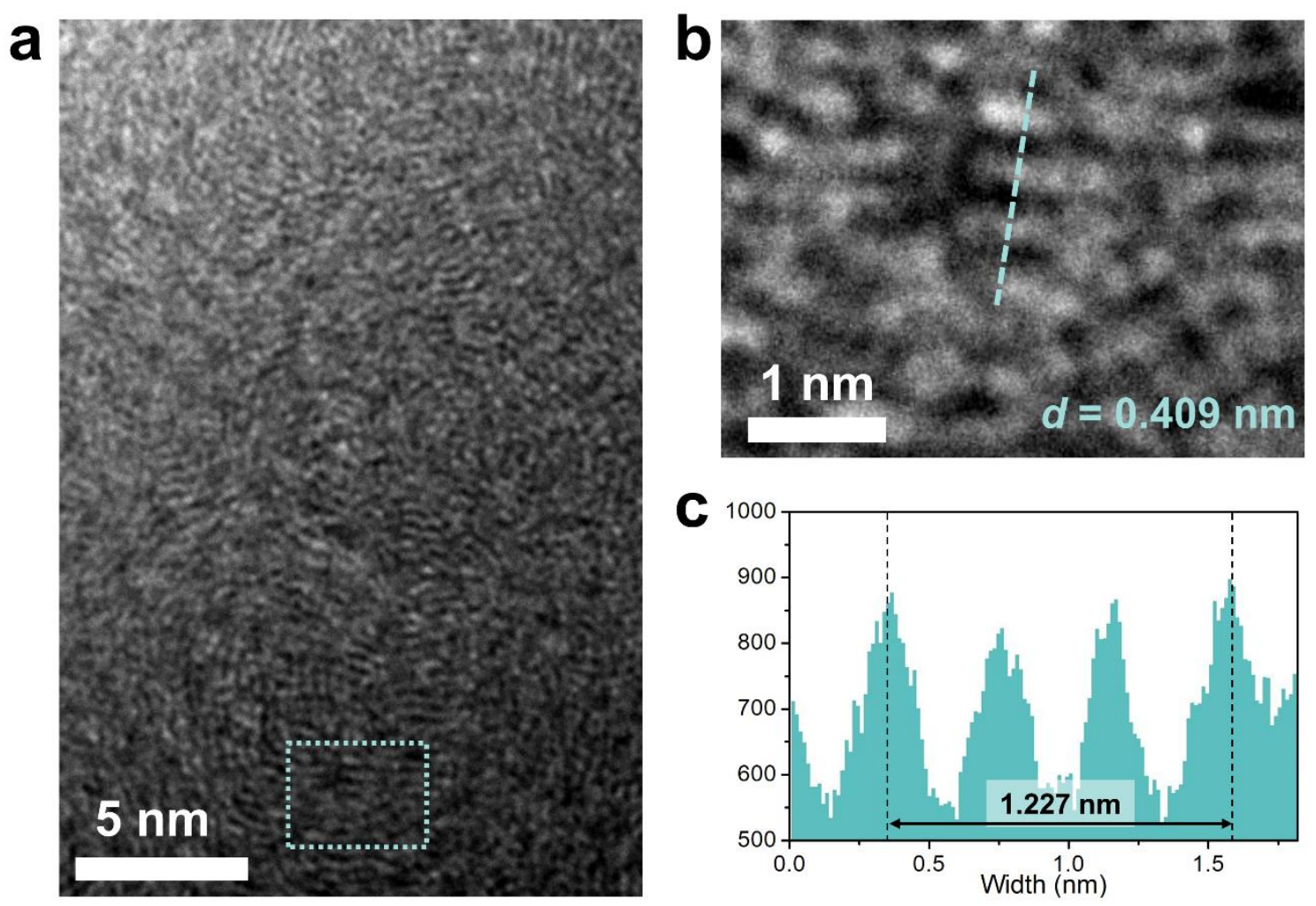

Figure S17. (a, b) HRTEM images of amorphous carbonaceous structures of HNCNS at different magnification and (c) corresponding interlayer spacing along the dashed line in (b). 

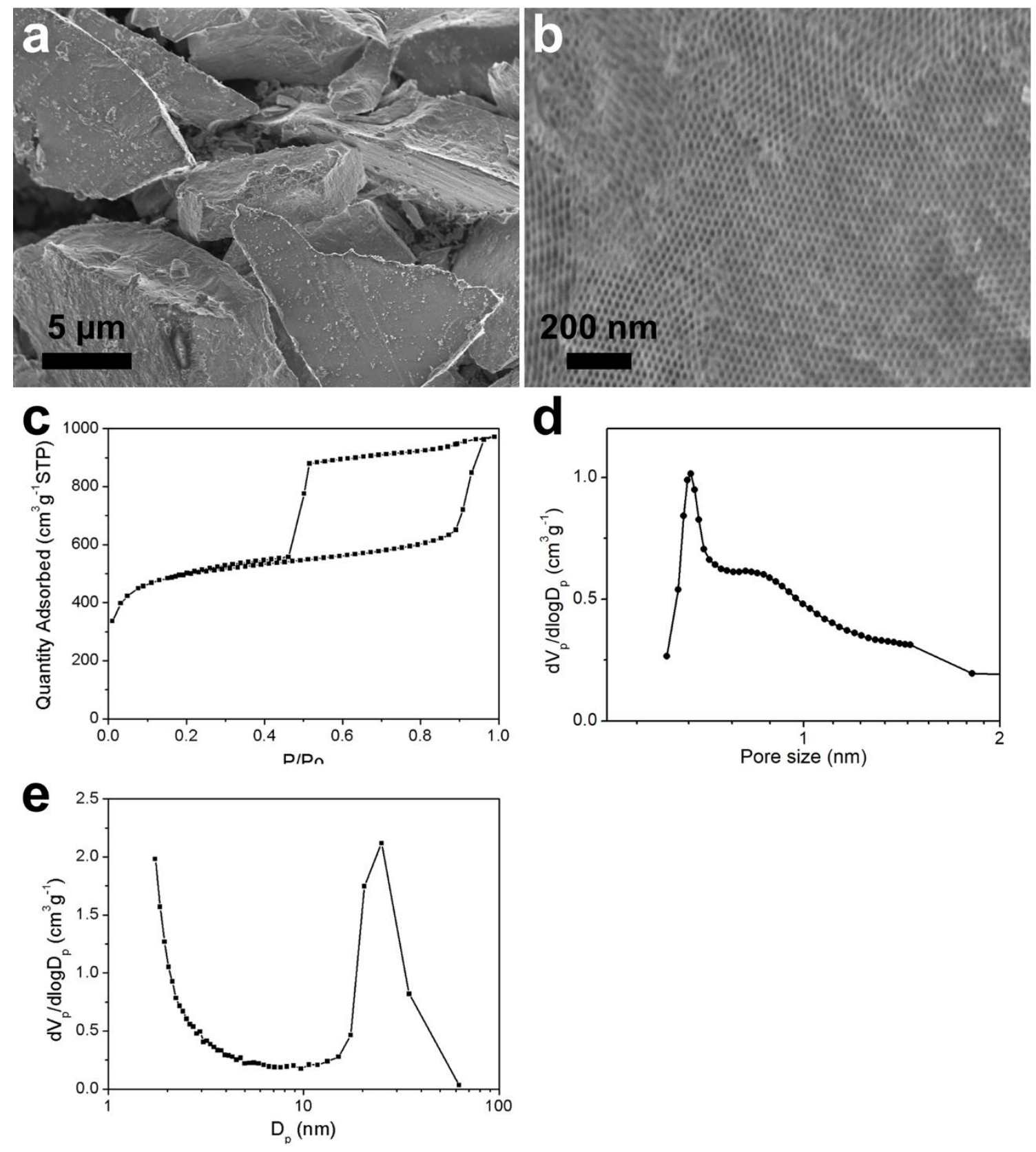

Figure S18. (a, b) SEM images of bulk hierarchical porous N-doped carbon (BHNC) at low and high magnification. (c) $\mathrm{N}_{2}$ physisorption isotherm and corresponding (d) micro- and (e) mesopore size distribution of BHNC.

SEM images of BHNC show irregular and monolithic bulk particles with size of a few micrometers and highly ordered mesoporous structures (Figure S14a, b). BHNC has a specific surface area of 1610 $\mathrm{m}^{2} \mathrm{~g}^{-1}$ (Figure S14c), micropores of $0.67 \mathrm{~nm}$ (Figure S14d) and mesopores of $25 \mathrm{~nm}$ (Figure S14e). 
a
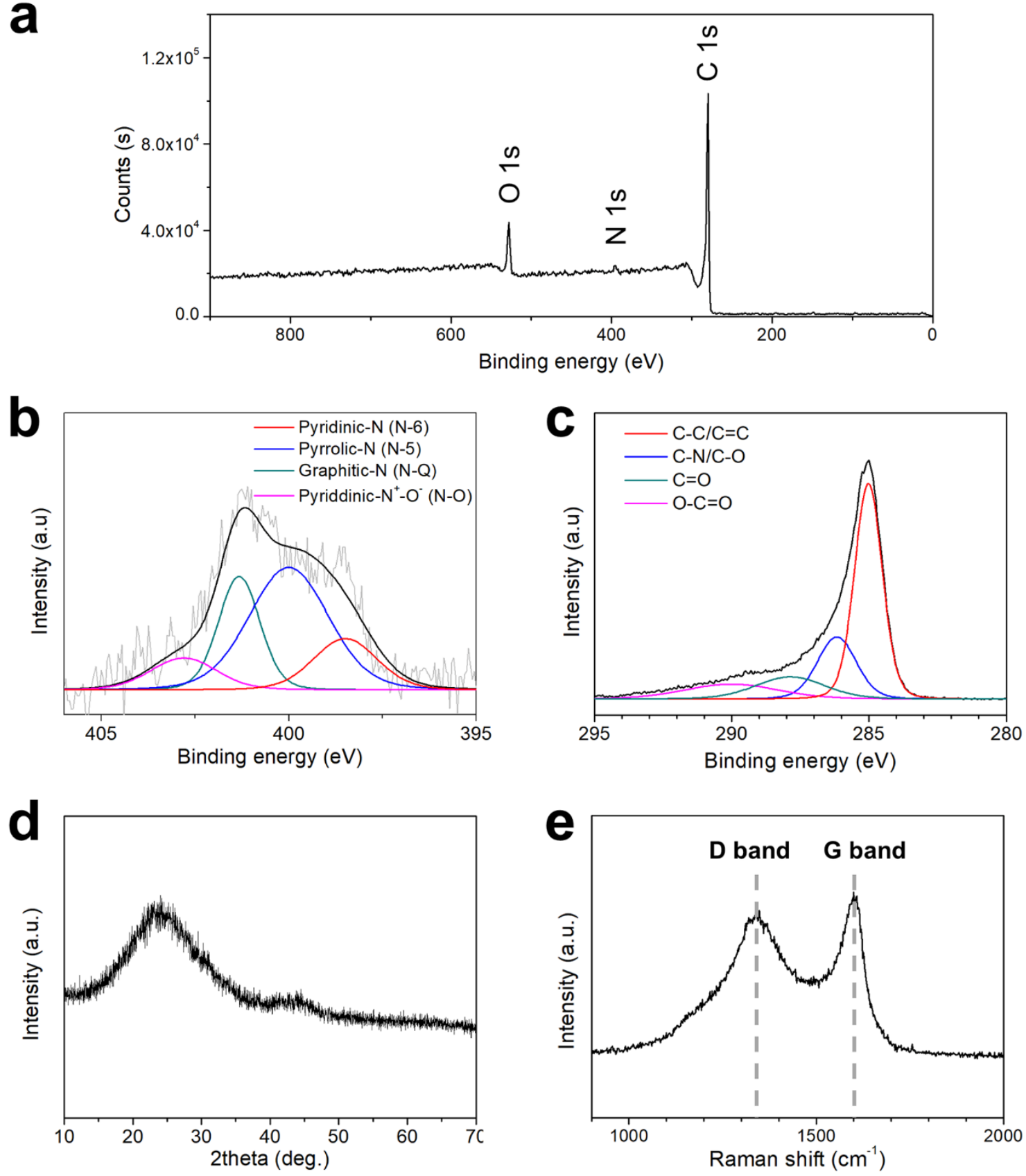

Figure S19. (a) XPS survey spectrum and (b, c) High-resolution XPS spectra of N 1s (b) and C 1s (c) for BHNC. (d) XRD pattern and (e) Raman spectrum of BHNC.

XPS analysis shows that BHNC is composed of $87.6 \% \mathrm{C}, 3.0 \% \mathrm{~N}$ and $9.4 \% \mathrm{O}$ (Figure S15a, Table S1).

The $\mathrm{N}$ 1s spectrum can be deconvoluted into four peaks at 398.4, 399.9, 401.1 and $402.5 \mathrm{eV}$, which correspond to N-6 (17.9\%), N-5 (45.1\%), N-Q (25.5\%) and N-O (11.5\%), respectively (Figure 
$\mathrm{S} 15 \mathrm{~b})$. The deconvoluted C $1 \mathrm{~s}$ spectrum is assigned to four peaks centered at 285.0, 286.1, 287.5 and $289.9 \mathrm{eV}$, corresponding to $\mathrm{C}-\mathrm{C} / \mathrm{C}=\mathrm{C}(53.0 \%), \mathrm{C}-\mathrm{N} / \mathrm{C}-\mathrm{O}(21.3 \%), \mathrm{C}=\mathrm{O}(13.6 \%)$ and $\mathrm{O}-\mathrm{C}=\mathrm{O}$ (12.1\%), respectively (Figure S15c and detailed XPS data are summarized in Table S2). The XRD pattern of BHNC exhibits two broad peaks at $23.2^{\circ}$ and $41.8^{\circ}$ indexed respectively to the (002) and (100) planes of the disordered carbonaceous structure (Figure S15d). The broad Raman bands are located at around $1340 \mathrm{~cm}^{-1}$ (D band) and $1600 \mathrm{~cm}^{-1}$ ( $\mathrm{G}$ band) and the intensity ratio of $\mathrm{D}$ band and $\mathrm{G}$ band $\left(\mathrm{I}_{\mathrm{D}} / \mathrm{I}_{\mathrm{G}}\right)$ is 0.92 (Figure $\mathrm{S} 15 \mathrm{e}$ ). These results indicate that $\mathrm{BHNC}$ has similar chemical properties to those of HNCNS. 

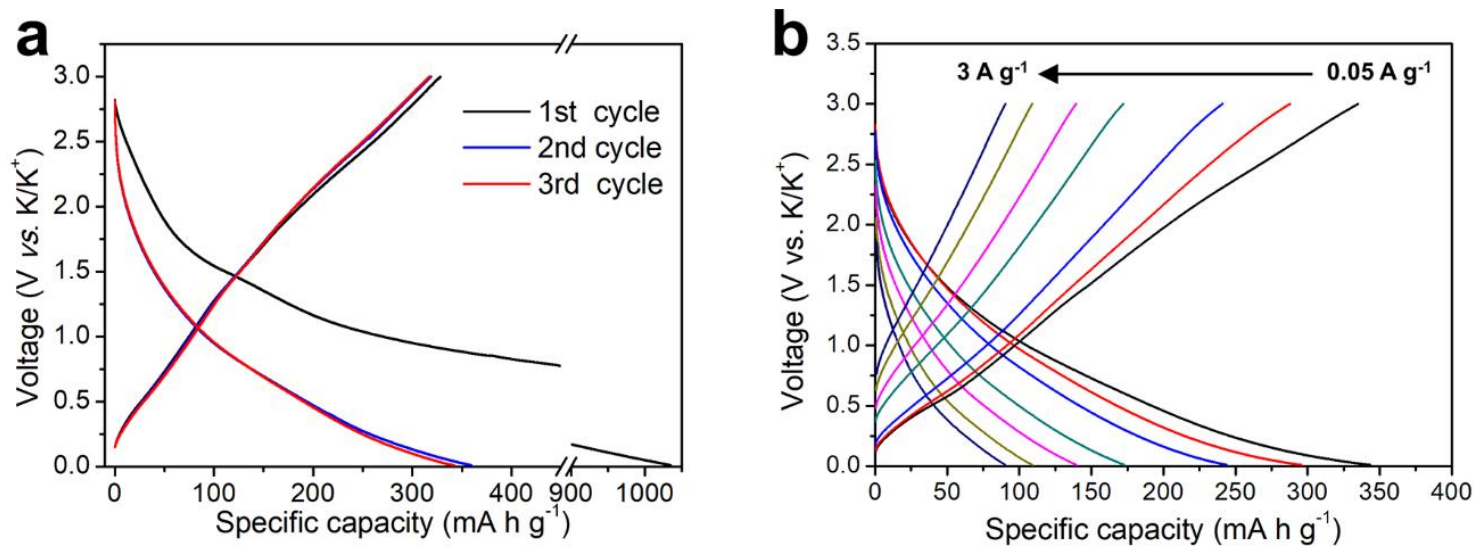

Figure S20. (a) Galvanostatic charge/discharge curves at $0.05 \mathrm{~A} \mathrm{~g}^{-1}$ in range of $0.01-3 \mathrm{~V}$ and (b) charge/discharge voltage profiles at various currents in range of $0.05-3 \mathrm{~A} \mathrm{~g}^{-1}$ of $\mathrm{HNCNS}$ electrode. 


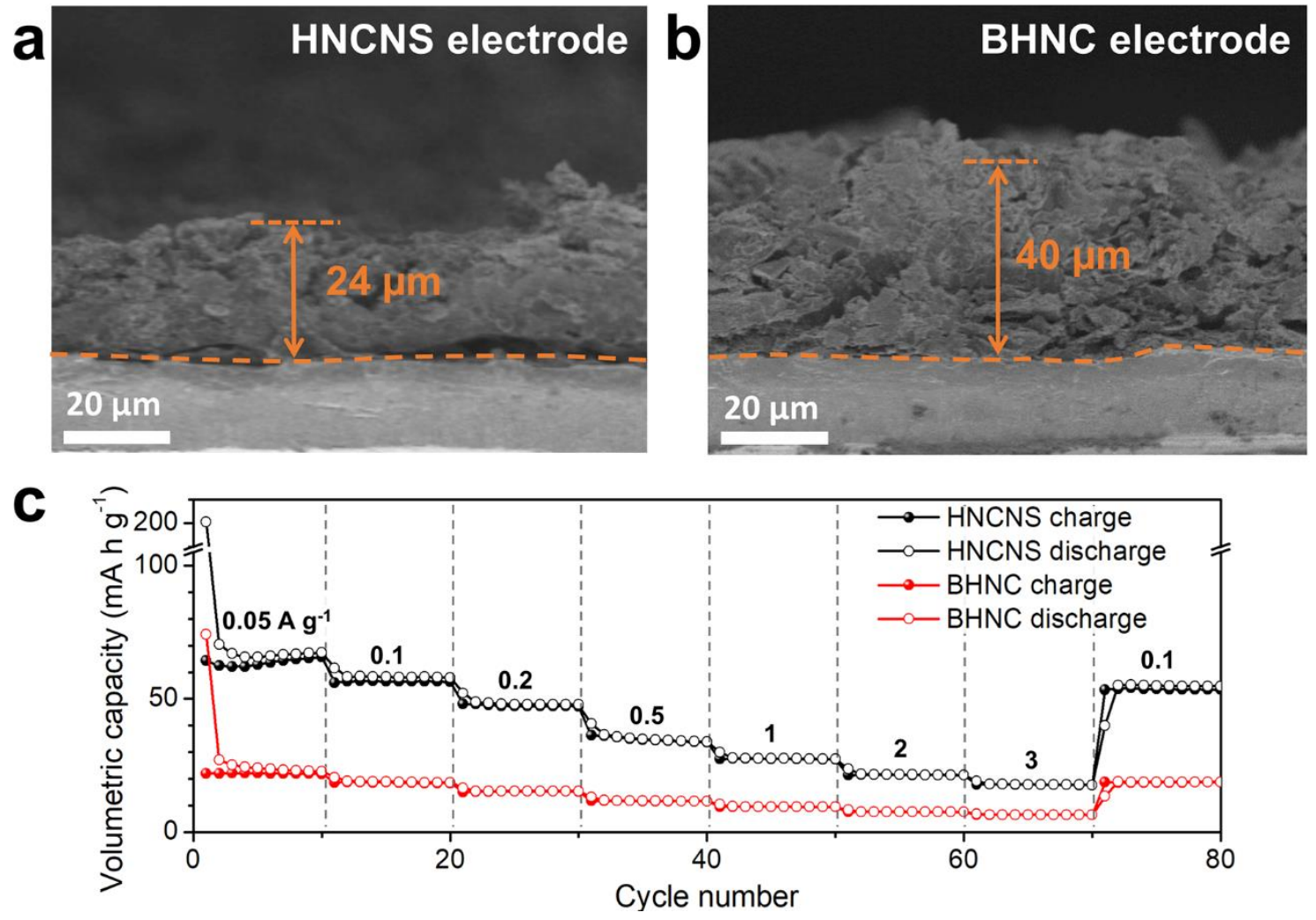

Figure S21. Side view of (a) HNCNS and (b) BHNC electrodes. (c) Comparison of volumetric capacities of HNCNS and BHNC electrodes at different current densities.

Volumetric performance has become a crucial criterion that gives a realistic view of the charge-storage capacity in the limited space of energy storage devices. Thus, mesoporous $2 \mathrm{D}$ nanosheets are highly desirable because they can pack more densely, and thus improve the volumetric capacity considerably, compared to bulk mesoporous particles. HNCNS electrode show crack-free packing with the thickness of $\sim 24 \mu \mathrm{m}$ (Figure S17a). However, BHNC electrode is $\sim 40 \mu \mathrm{m}$ thick, and forms some cracks due to its large particle size and nonuniform particle morphology (Figure S17b). The higher electrode density of HNCNS contributes to the increase in volumetric capacity (Table S4). The HNCNS electrode shows higher volumetric capacities than BHNC electrode at all current densities. For instance, HNCNS electrode achieved 3.1 times higher volumetric capacity $\left(59 \mathrm{~mA} \mathrm{~h} \mathrm{~cm}^{-3}\right)$ than BHNC electrode $\left(19 \mathrm{~mA} \mathrm{~h} \mathrm{~cm}^{-3}\right)$ at $0.1 \mathrm{~mA} \mathrm{~g}^{-1}$ (Figure S17c). 

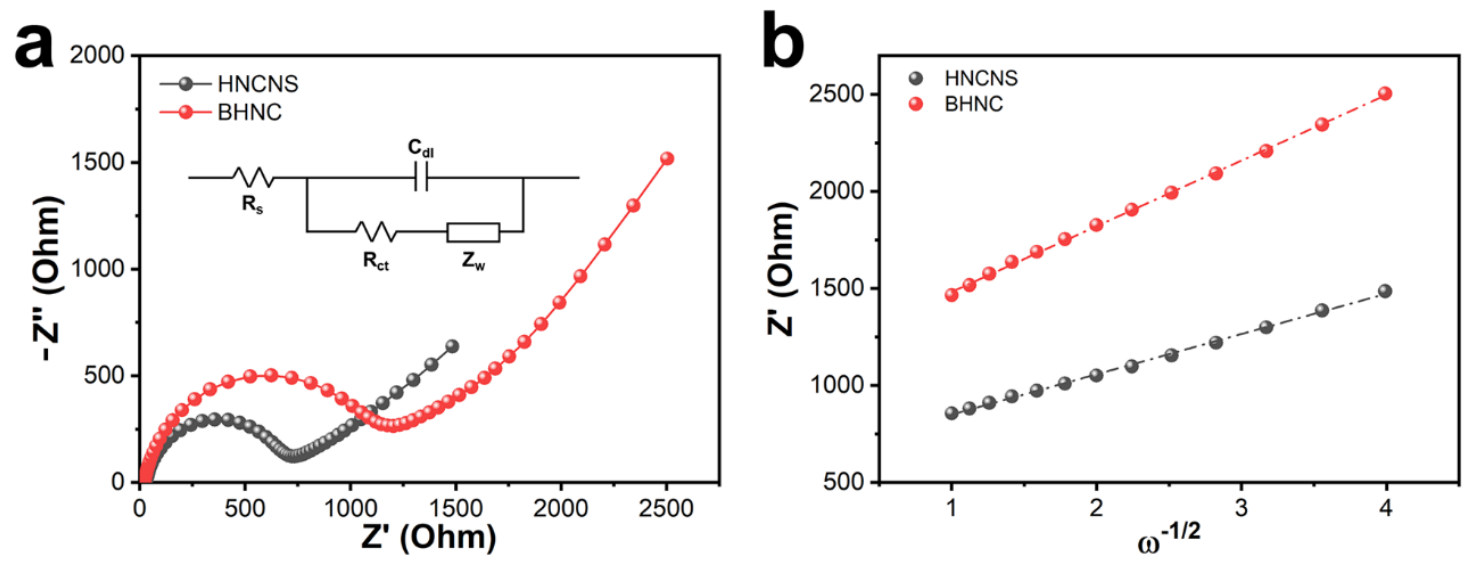

Figure S22. (a) Nyquist plots of HNCNS and BHNC after cycling (the inset shows the relevant equivalent circuit); (b) the linear fits of the $Z^{\prime} v$ s. $\omega^{-1 / 2}$ in the low frequency region.

The electrochemical impedance spectroscopy (EIS) technique was used to analyze the morphological influence on the electrode kinetics of HNCNS. Nyquist plots reveal that HNCNS has lower chargetransfer resistance than BHNC (Figure S22a), which indicates that both charge-transfer and $\mathrm{K}^{+}$ exchange at electrolyte/electrode interfaces were enhanced. To compare $\mathrm{K}^{+}$diffusivity of HNCNS and BHNC, the $\mathrm{K}^{+}$diffusion coefficients $\left(\mathrm{D}_{\mathrm{K}}\right)$ were calculated by the low frequency region of Nyquist plots (Figure S22b) according to the following equation:

$$
\mathrm{D}_{\mathrm{K}}=\frac{1}{2}\left(\frac{R T}{A n^{2} F^{2} C_{K} \sigma}\right)^{2}
$$

where $\mathrm{D}_{\mathrm{K}}$ is the $\mathrm{K}^{+}$diffusion coefficient; $\mathrm{R}$ is the gas constant; $\mathrm{T}$ is the experiment temperature; $\mathrm{A}$ is the active surface area of electrode; $\mathrm{n}$ is the number of transferred electrons; $\mathrm{F}$ is the Faraday constant; $\mathrm{C}_{\mathrm{K}}$ is the concentration of $\mathrm{K}^{+}$and $\sigma$ is the Warburg factor which is determined as the slope of linear relationship between $\mathrm{Z}^{\prime}$ and $\omega^{-1 / 2}$ in the low frequency region. HNCNS has the higher $\mathrm{K}^{+}$diffusion 
coefficient $\left(3.80 \times 10^{-13} \mathrm{~cm}^{2} \mathrm{~s}^{-1}\right)$ than that of BHNC $\left(1.42 \times 10^{-13} \mathrm{~cm}^{2} \mathrm{~s}^{-1}\right)$, indicating that ultra-thin $2 \mathrm{D}$ morphologies of nanosheets promote solid state diffusion (Table S4). 


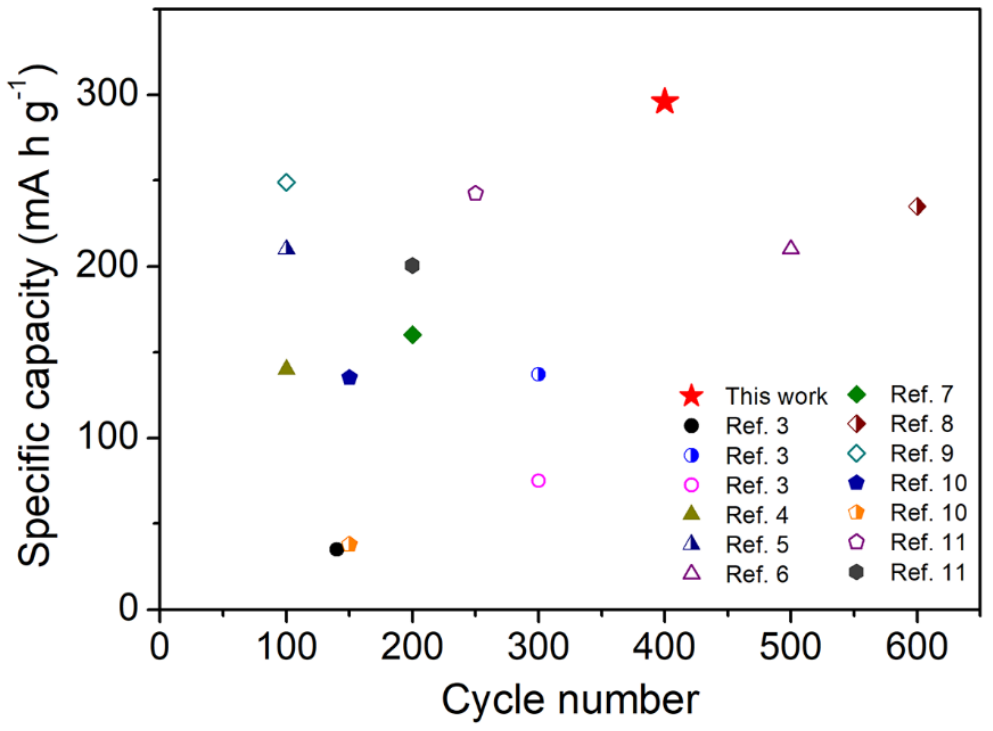

Figure S23. Comparison of cycling performance of our HNCNS and other types of carbonaceous anodes at low current density $\left(0.1 \mathrm{~A} \mathrm{~g}^{-1}\right)$. Details in Table S5. 


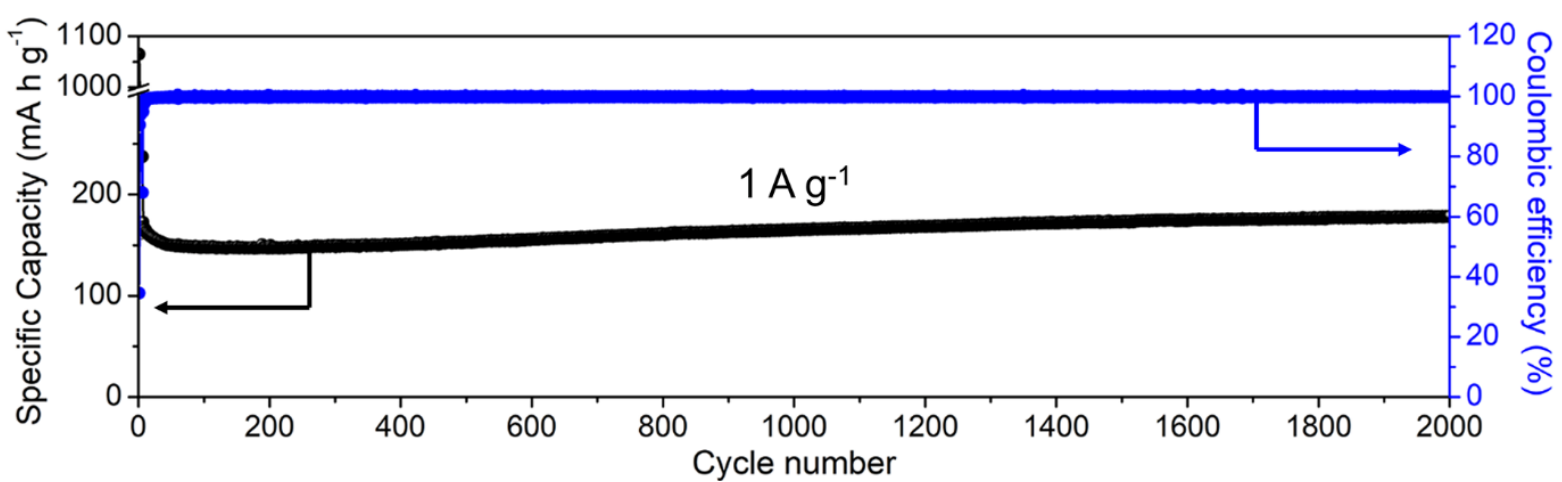

Figure S24. Long-term cyclability of HNCNS electrode at $1 \mathrm{~A} \mathrm{~g}^{-1}$ and the coulombic efficiency. 

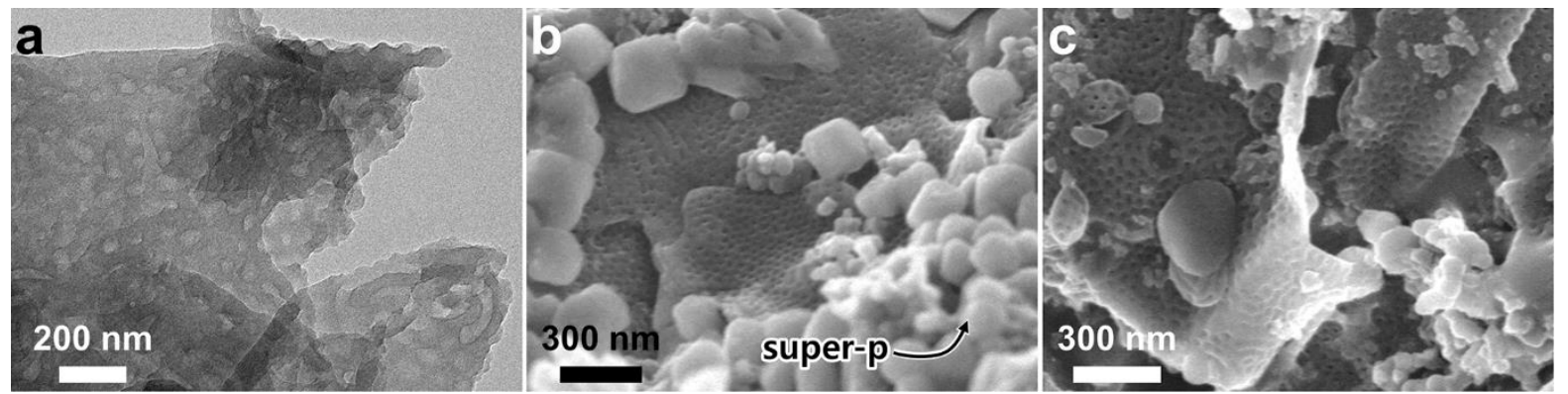

Figure S25. (a) TEM and (b, c) SEM images of HNCNS after cycling at current density of $1 \mathrm{Ag}^{-1}$. 
Table S1. Element contents of HNCNS and detailed XPS data for N 1s and C 1s.

\begin{tabular}{|c|c|c|c|c|}
\hline & \multicolumn{4}{|c|}{ Element contents (at\%) } \\
\hline & $\mathrm{C}$ & & & $\mathrm{O}$ \\
\hline \multirow[t]{2}{*}{ HNCNS } & 89.0 & & & 7.60 \\
\hline & $\mathrm{N}-6$ & $\mathrm{~N}-5$ & $\mathrm{~N}-\mathrm{Q}$ & $\mathrm{N}-\mathrm{O}$ \\
\hline Peak center $(\mathrm{eV})$ & 398.2 & 399.7 & 400.9 & 402.1 \\
\hline \multirow[t]{2}{*}{$\%$ of total $\mathrm{N} 1 \mathrm{~s}$} & 19.2 & 41.0 & 26.8 & 13.0 \\
\hline & $\mathrm{C}-\mathrm{C} / \mathrm{C}=\mathrm{C}$ & $\mathrm{C}-\mathrm{N} / \mathrm{C}-\mathrm{O}$ & $\mathrm{C}=\mathrm{O}$ & $\mathrm{O}-\mathrm{C}=\mathrm{O}$ \\
\hline Peak center $(\mathrm{eV})$ & 285.0 & 286.0 & 287.1 & 289.3 \\
\hline$\%$ of total C $1 \mathrm{~s}$ & 56.6 & 20.0 & 12.0 & 11.4 \\
\hline
\end{tabular}


Table S2. The relation between synthetic conditions and the physical properties of carbon materials.

\begin{tabular}{|c|c|c|c|c|}
\hline Block copolymer & $\begin{array}{c}\text { Homopolymer } / \mathrm{BCP} \\
\text { mass ratio }\end{array}$ & $\begin{array}{l}\text { Resultant } \\
\text { shape }\end{array}$ & $\begin{array}{c}\text { Size or } \\
\text { thickness (nm) }\end{array}$ & $\begin{array}{l}\text { Mesopore } \\
\text { size (nm) }\end{array}$ \\
\hline \multirow{4}{*}{$\begin{array}{c}\text { PEO- } b \text {-PS } \\
\left(34.1 \mathrm{~kg} \mathrm{~mol}^{-1}\right)\end{array}$} & $\begin{array}{c}0 \\
\text { (no homopolymer) }\end{array}$ & Bulk particle & $5-10 \mu \mathrm{m}$ & 25 \\
\hline & 20 & Nanosheet & 75 & 25 \\
\hline & 40 & Nanosheet & 8.6 & 25 \\
\hline & 200 & Nanodisk & 5.7 & $\begin{array}{c}\text { No } \\
\text { mesopore }\end{array}$ \\
\hline $\begin{array}{c}\text { PEO- } b \text {-PS } \\
\left(52.0 \mathrm{~kg} \mathrm{~mol}^{-1}\right)\end{array}$ & 40 & Nanosheet & 8.6 & 46 \\
\hline $\begin{array}{l}\text { PEO- } b \text {-PMMA } \\
\left(29.4 \mathrm{~kg} \mathrm{~mol}^{-1}\right)\end{array}$ & 40 & sphere & $\sim 200$ & 12 \\
\hline F127 & 40 & sphere & $\sim 200$ & 2.9 \\
\hline No BCP & 40 & sphere & $100-600$ & $\begin{array}{c}\text { No } \\
\text { mesopore }\end{array}$ \\
\hline
\end{tabular}


Table S3. Element contents of BHNC and detailed XPS data for N 1 s and C $1 \mathrm{~s}$.

\begin{tabular}{|c|c|c|c|c|}
\hline & \multicolumn{4}{|c|}{ Element contents (at\%) } \\
\hline \multirow{3}{*}{ BHNC } & $\mathrm{C}$ & \multicolumn{2}{|c|}{$\mathrm{N}$} & $\mathrm{O}$ \\
\hline & 87.6 & \multicolumn{2}{|c|}{3.00} & 9.40 \\
\hline & $\mathrm{N}-6$ & $\mathrm{~N}-5$ & $\mathrm{~N}-\mathrm{Q}$ & $\mathrm{N}-\mathrm{O}$ \\
\hline Peak center $(\mathrm{eV})$ & 398.4 & 399.9 & 401.1 & 402.5 \\
\hline \multirow[t]{2}{*}{$\%$ of total $\mathrm{N} 1 \mathrm{~s}$} & 17.9 & 45.1 & 25.5 & 11.5 \\
\hline & $\mathrm{C}-\mathrm{C} / \mathrm{C}=\mathrm{C}$ & $\mathrm{C}-\mathrm{N} / \mathrm{C}-\mathrm{O}$ & $\mathrm{C}=\mathrm{O}$ & $\mathrm{O}-\mathrm{C}=\mathrm{O}$ \\
\hline Peak center $(\mathrm{eV})$ & 285.0 & 286.1 & 287.5 & 289.9 \\
\hline$\%$ of total C $1 \mathrm{~s}$ & 53.0 & 21.3 & 13.6 & 12.1 \\
\hline
\end{tabular}

Table S4. Physico- and electrochemical property comparison of HNCNS and BHNC

\begin{tabular}{ccc}
\hline & HNCNS & BHNC \\
\hline Surface area $\left(\mathrm{m}^{2} \mathrm{~g}^{-1}\right)$ & 1950 & 1610 \\
Micropore size $(\mathrm{nm})$ & 0.65 & 0.67 \\
Mesopore size $(\mathrm{nm})$ & 25 & 25 \\
$\mathrm{I}_{\mathrm{D}} / \mathrm{I}_{\mathrm{G}}$ & 0.93 & 0.92 \\
Electrode density $\left(\mathrm{g} \mathrm{cm}^{-3}\right)$ & 0.20 & 0.14 \\
Nitrogen content $\left(\mathrm{at}^{\mathrm{a}}\right)$ & 3.40 & 3.00 \\
$\mathrm{~K}^{+}$diffusion coefficient $\left(10^{-13} \mathrm{~cm}^{2} \mathrm{~s}^{-1}\right)$ & 3.80 & 1.42 \\
\hline
\end{tabular}


Table S5. Comparison of HNCNS electrode with reported carbonaceous anodes in KIBs at low current density $\left(0.1 \mathrm{~A} \mathrm{~g}^{-1}\right)$.

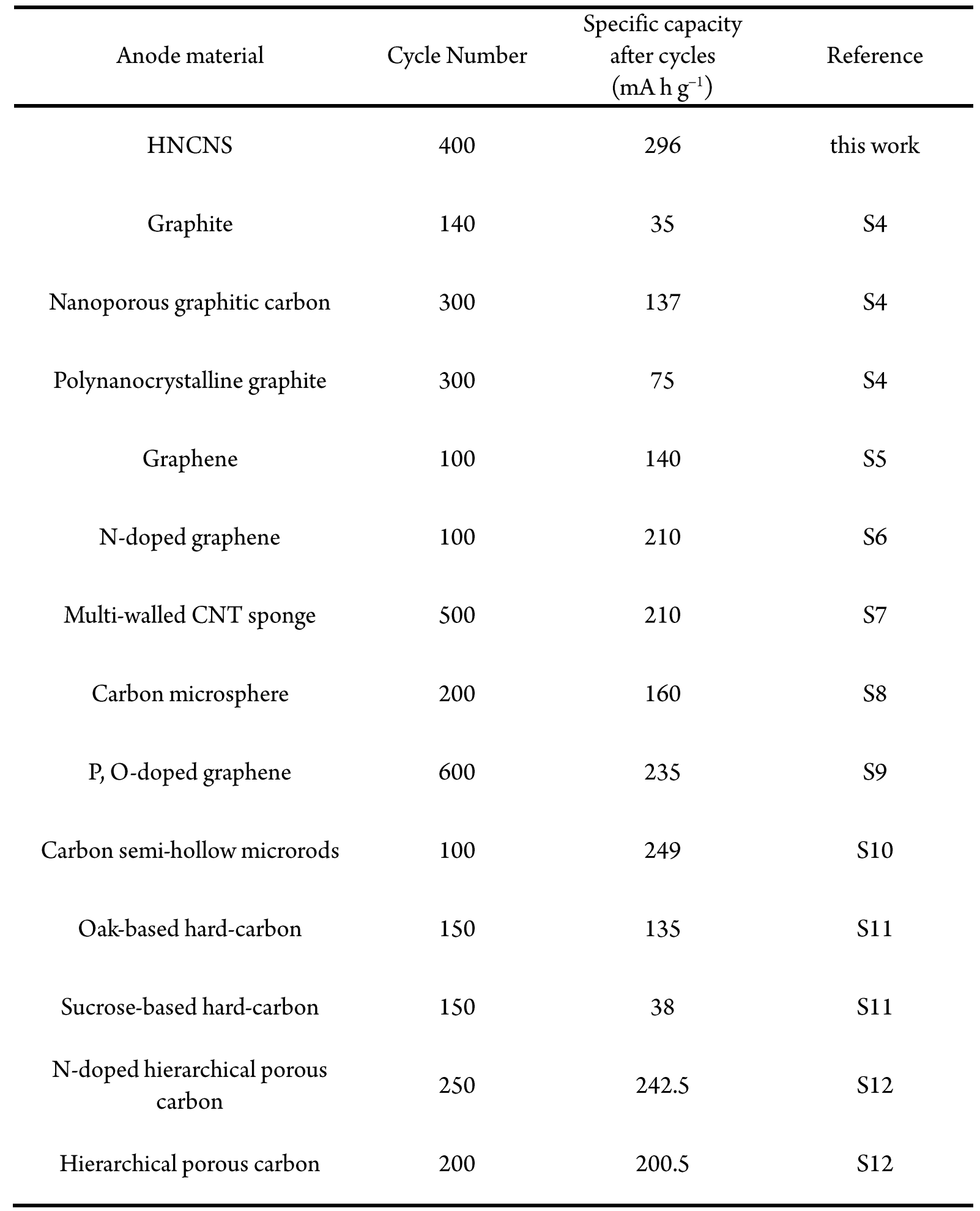


Table S6. Electrochemical performance comparison of HNCNS anode with previously reported the carbonaceous anode materials for KIBs.

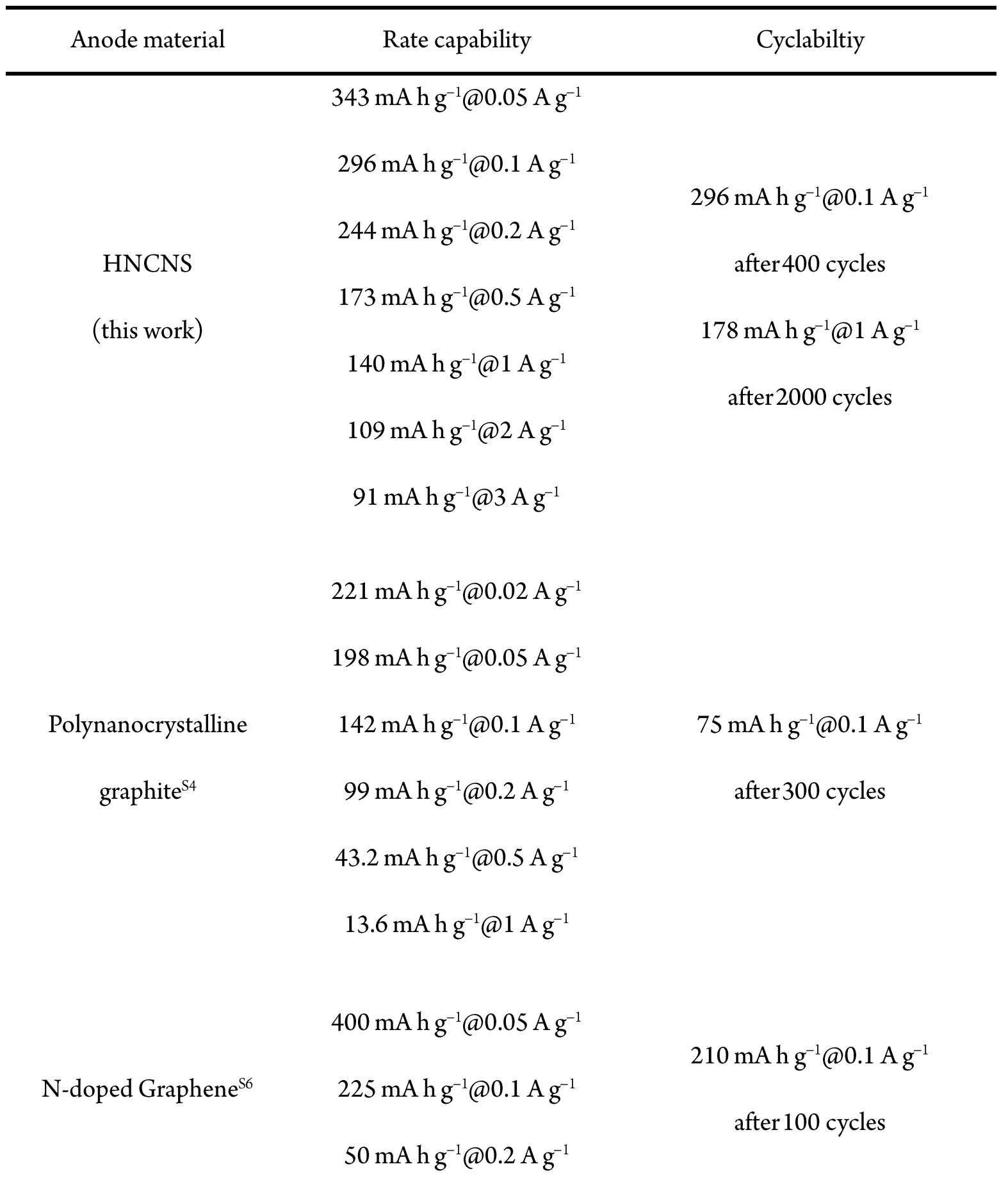


193 mAhg g-1@0.14 A g ${ }^{-1}$

157 mAh g-1@0.28. g g

Carbon microsphere $\mathrm{S}^{\mathrm{8}} \quad 135 \mathrm{mAh} \mathrm{g}^{-1} @ 0.558 \mathrm{Ag}^{-1}$

81 mAhg g-1@1.4 $\mathrm{Ag}^{-1}$

45 mA h g ${ }^{-1} @ 2.8 \mathrm{Ag}^{-1}$

220 mAhg g-1@0.028 A g ${ }^{-1}$

173 mAhg ${ }^{-1} @ 0.056 \mathrm{Ag}^{-1}$

Hard carbon $^{\mathrm{S} 13}$

139 mAhg g-1@0.14 A g ${ }^{-1}$

110 mAhg g-1@0.279 g g $^{-1}$

60 mAhg g-1@0.558 Ag g

264 mAh g ${ }^{-1} @ 0.028$ A g $^{-1}$

210 mAh g ${ }^{-1} 00.279 \mathrm{Ag}^{-1} \quad 150 \mathrm{mAhg}^{-1} @ 0.558 \mathrm{Ag}^{-1}$

Soft carbon ${ }^{\text {S14 }}$

$$
\begin{aligned}
& 185 \text { mA h g }{ }^{-1} @ 0.558 \mathrm{Ag}^{-1} \\
& 140 \text { mA h g-1@1.4 A g }{ }^{-1}
\end{aligned}
$$$$
286 \mathrm{mAhg}^{-1} @ 0.05 \mathrm{Ag}^{-1}
$$$$
255 \text { mAhg g-1@0.1 Ag }{ }^{-1}
$$

Mesoporous carbon ${ }^{\mathrm{S} 15}$
$160 \mathrm{mAhg}^{-1} @ 0.14 \mathrm{Ag}^{-1}$

after 200 cycles

155 mAhg-1@0.14 Ag $^{-1}$ after 200 cycles
198 mAhg g-1@0.2 Ag ${ }^{-1}$
219 mA h g g $^{-1} 0.2$ A g $^{-1}$

$186 \mathrm{mAhg}^{-1} @ 0.5 \mathrm{Ag}^{-1}$

$$
144 \text { mA h g-1@1 A g }{ }^{-1}
$$
after 200 cycles

147 mAhg ${ }^{-1} @ 1$ Ag $^{-1}$

after 1000 cycles 


\begin{tabular}{|c|c|c|}
\hline \multirow{4}{*}{ Pencil-trace carbon ${ }^{\mathrm{S} 16}$} & 285 mAh g ${ }^{-1} @ 0.1 \mathrm{Ag}^{-1}$ & \\
\hline & $230 \mathrm{mAhg} \mathrm{g}^{-1} @ 0.2 \mathrm{Ag}^{-1}$ & $170 \mathrm{mAhg} \mathrm{g}^{-1} @ 0.4 \mathrm{Ag}^{-1}$ \\
\hline & 190 mA h g ${ }^{-1} @ 0.5 \mathrm{Ag}^{-1}$ & after 350 cycles \\
\hline & $110 \mathrm{mAhg} \mathrm{g}^{-1} @ 1 \mathrm{Ag}^{-1}$ & \\
\hline
\end{tabular}




\section{References}

(S1) Kim, S.; Jeong, I.; Hwang, J.; Ko, M.; Lee, J, Simple Synthesis of Multiple Length-Scale Structured $\mathrm{Nb}_{2} \mathrm{O}_{5}$ with Macrodomain-Integrated Mesoporous Frameworks. Chem. Commun. 2017, 53 (29), 4100-4103

(S2) Templin, M.; Franck, A.; Du Chesne, A.; Leist, H.; Zhang, Y.; Ulrich, R.; Schädler, V.; Wiesner, U., Organically modified aluminosilicate mesostructures from block copolymer phases. Science 1997, 278 (5344), 1795-1798.

(S3) Joensson, J.-E.; Hassander, H.; Toernell, B., Polymerization conditions and the development of a core-shell morphology in PMMA/PS latex particles. 1. Influence of initiator properties and mode of monomer addition. Macromolecules 1994, 27 (7), 1932-1937.

(S4) Xing, Z.; Qi, Y.; Jian, Z.; Ji, X., Polynanocrystalline graphite: a new carbon anode with superior cycling performance for K-ion batteries. ACS Appl. Mater. Interfaces 2016, 9 (5), 4343-4351.

(S5) Share, K.; Cohn, A. P.; Carter, R. E.; Pint, C. L., Mechanism of potassium ion intercalation staging in few layered graphene from in situ Raman spectroscopy. Nanoscale 2016, 8 (36), 16435-16439.

(S6) Share, K.; Cohn, A. P.; Carter, R.; Rogers, B.; Pint, C. L., Role of nitrogen-doped graphene for improved highcapacity potassium ion battery anodes. ACS Nano 2016, 10 (10), 9738-9744.

(S7) Wang, Y.; Wang, Z.; Chen, Y.; Zhang, H.; Yousaf, M.; Wu, H.; Zou, M.; Cao, A.; Han, R. P., Hyperporous sponge interconnected by hierarchical carbon nanotubes as a high-performance potassium-ion battery Anode. Adv. Mater. 2018, 30 (32), 1802074.

(S8) Jian, Z.; Hwang, S.; Li, Z.; Hernandez, A. S.; Wang, X.; Xing, Z.; Su, D.; Ji, X., Hard-soft composite carbon as a long-cycling and high-rate anode for potassium-ion batteries. Adv. Funct. Mater. 2017, 27 (26), 1700324.

(S9) Ma, G.; Huang, K.; Ma, J.-S.; Ju, Z.; Xing, Z.; Zhuang, Q.-c., Phosphorus and oxygen dual-doped graphene as superior anode material for room-temperature potassium-ion batteries. J. Mater. Chem. A 2017, 5 (17), 7854 7861.

(S10) Wang, X.; Han, K.; Qin, D.; Li, Q.; Wang, C.; Niu, C.; Mai, L., Polycrystalline soft carbon semi-hollow microrods as anode for advanced K-ion full batteries. Nanoscale 2017, 9 (46), 18216-18222.

(S11) Prabakar, S. R.; Han, S. C.; Park, C.; Bhairuba, I. A.; Reece, M. J.; Sohn, K.-S.; Pyo, M., Spontaneous Formation of Interwoven Porous Channels in Hard-Wood-Based Hard-Carbon for High-Performance Anodes in PotassiumIon Batteries. J. Electrochem. Soc. 2017, 164 (9), A2012-A2016.

(S12) Gao, C.; Wang, Q.; Luo, S.; Wang, Z.; Zhang, Y.; Liu, Y.; Hao, A.; Guo, R., High performance potassium-ion battery anode based on biomorphic N-doped carbon derived from walnut septum. J. Power Sources 2019, 415, 165-171.

(S13) Li, Y.; Adams, R. A.; Arora, A.; Pol, V. G.; Levine, A. M.; Lee, R. J.; Akato, K.; Naskar, A. K.; Paranthaman, M. P., Sustainable potassium-ion battery anodes derived from waste-tire rubber. J. Electrochem. Soc. 2017, 164 (6), A1234-A1238.

(S14) Jian, Z.; Luo, W.; Ji, X., Carbon electrodes for K-ion batteries. J. Am. Chem. Soc. 2015, 137 (36), 11566-11569.

(S15) Wang, W.; Zhou, J.; Wang, Z.; Zhao, L.; Li, P.; Yang, Y.; Yang, C.; Huang, H.; Guo, S., Short-range order in mesoporous carbon boosts potassium-ion battery performance. Adv. Energy Mater. 2018, 8 (5), 1701648.

(S16) Tai, Z.; Liu, Y.; Zhang, Q.; Zhou, T.; Guo, Z.; Liu, H. K.; Dou, S. X., Ultra-light and flexible pencil-trace anode for high performance potassium-ion and lithium-ion batteries. Green Energy Environ. 2017, 2 (3), 278-284. 